This is the accepted version of the following article: Alfredo de la Escosura-Muñiza, Arben Merkoçi. Nanochannels for electrical biosensing. TrAC - Trends in Analytical Chemistry, Vol.79 (2016), pp 134150; which has been published in final form at https://doi.org/10.1016/j.trac.2015.12.003.

(C) 2016. This manuscript version is made available under the CC-BY-NC-ND 4.0 license http://creativecommons.org/licenses/by-nc-nd/4.0/

\title{
Nanochannels for electrical biosensing
}

Alfredo de la Escosura-Muñiz, Arben Merkoçil, ${ }^{1 *}$

${ }^{1}$ Catalan Institute of Nanoscience and Nanotechnology (ICN2), CSIC and The

Barcelona Institute of Science and Technology, Campus UAB, Bellaterra, 08193

Barcelona, Spain.

${ }^{2}$ ICREA - Institucio Catalana de Recerca i Estudis Avançats, 08010 Barcelona, Spain

*Corresponding author: arben.merkoci@icn.cat Phone number: +34937374604

\begin{abstract}
This review shows the recent trends on the use of both single and array nanochannels for electrical biosensing applications. Some general considerations on the principles of the stochastic sensing, together with an overview about the common routes for nanochannels preparation before focusing on the applications for DNA, protein, virus, toxin and other analytes detection are given. Emerging materials used to obtain nanochannels, such as graphene and its analogues as well as novel systems based on the use of nanoparticles in combination with nanochannels are discussed. Aspects related to the analytical performance of the developed devices are also discussed. Finally prospects for future improvements and applications of this technology are included.
\end{abstract}

Keywords: Nanopores; nanochannels; nanoparticle; electrical; electrochemical; voltammetry; electrochemical impedance; capacitive; conductometry; resistivity; biosensing; protein sensing; DNA sensing. 


\section{INTRODUCTION}

One of the leading sectors of state-of-the-art nanoscience and nanotechnology is focused on the development and application of novel biosensing systems. Measurement of clinical parameters, monitoring of environmental pollutants, detection of pathogens, and other industrial and safety and security related detection are reported in the wide range of biosensing systems that are under commercial development. ${ }^{1,2}$

One of the challenges for providing biosensing devices to end-users relies in the modification of current technologies so as to make them run on everyday equipment, rather than on specialized apparatuses. Recent advances in nanomaterials and nanotechnologies research are allowing the development of either highly improved biosensing systems or brand new ones fulfilling the requirements of cost-effective and user-friendly devices. ${ }^{3-5}$

Particularly, nanopores/nanochannels have emerged in the last decade as materials with powerful analytic capability for biosensing applications. Natural protein-based ion channels have inspired artificial electrical biosensing systems based on both single nanochannels and nanochannel arrays with outstanding performance for the detection of a variety of analytes, including protein biomarkers and DNA between others. The potential ability of these devices for DNA sequencing are one of the most exciting perspectives of the nowadays nanobiotechnology.

Electrical sensing using single nanopores have been object of several reviews. ${ }^{6-14}$ In addition biosensing applications of nanochannel arrays, but mostly related to optical approaches which has drawbacks in terms of application in real samples beside inappropriateness of the detection principle for in-field /point of care applications is also found in the literature. ${ }^{15,16}$ In contrast, in this review we focus for the first time in a more analytical application-related perspective on single nanochannel-based electrical sensing 
platforms, giving a special relevance to the emerging materials used for drilling single nanochannels as alternative to the traditional silicon oxide/silicon nitride membranes, such as graphene and its analogues (hafnium oxide, boron nitride and molybdenum disulphide). We also highlight the recent trends in the development of innovative electrical approaches based on nanochannel arrays, in combination with the use of nanoparticles.

For a better understanding of this review, it is important to clarify first that "nanopore" is defined as a pore with a diameter in the range 1-100 $\mathrm{nm}$, and a depth shorter than its diameter. The term "nanochannel" applies when the pore depth is much larger than the diameter which makes them more selective on the translocated analytes. ${ }^{17}$ In spite of these differences, both terms are currently in common mutual use.

\section{BASIC CONCEPTS: FROM THE COULTER COUNTER TO THE STOCHASTIC SENSING}

The precursor of the nanochannels-based biosensing systems was the microparticle counter device developed by Wallace Coulter in the 50's. ${ }^{18-20}$ Mobility, surface charge, and concentration of micro-sized analytes can be evaluated by simply measuring changes in the electrical conductance (electric current or voltage pulse) between two chambers separated by a microchannel when such analyte passes through the channel. Commercial devices based on such principle are routinely used in the industry of painting and ceramics as well as in hospitals (for cells counting/determination) between other applications (Figure 1A).

This device evolved from micro- to nanochannels-based ones, shown to be able to detect molecules in the nanoscale such as ssDNA and proteins (Figure 1B). However, the preparation of two chambers separated by a thin membrane containing a single pore with 
nanometer size represents a major technical challenge. As in many cases, nature has served here as inspiration, providing with alternatives such as the use of pore forming toxins (PFTs). ${ }^{21}$ PFTs are protein exotosins typically produced by bacteria such as Clostridium septicum o Staphilococus aureus. They are the most common class of bacterial protein toxins and the responsible of the most important virulence factors. These toxins are secreted by bacteria in a water-soluble form. Their monomers diffuse towards the target cells, bind them via specific receptors and oligomerize forming ring-like complexes. The pore formation leads to ionic imbalances in the cells and the subsequent cell death (in the case of erythrocytes, to cell lysis). In some cases PFTs also transport secondary toxins into the cells via the pores, so the toxic effect is even higher.

As example of PFTs we can find i.e. $\alpha$-hemolysin, anthrax toxin or pneumolysin, between others. In both cases, they form heptamers which are the responsible of the pore formation. The structures of the pores formed by $\alpha$-hemolysin and the anthrax toxin are shown in Figure 1C while the mechanism of action of these toxins is illustrated in Figure $1 D$.

The insertion of the $\alpha$-hemolysin bacterial protein pore in artificial lipid bilayer membranes separating two chambers filled with an electrolyte solution was the pioneer approach to build these biomimetic nanochannels. ${ }^{22-24}$ A drop in electric potential close to the nanochannel is created when an external electrical field is applied across the membrane, producing an ionic flow and inducing a measurable current. Charged biopolymers (i.e. DNA) are first attracted by the electric field in a random way and then forced to pass through the channel. This pass, also known as "translocation" produces a displacement of electrolytes in the channel, leading to a sudden decrease in conductivity which can be recorded with an electrometer. 
The ability to use a single channel as an analytical sensor, was reported for the first time in the early 1990s by Kasianowicz and Bezrukov who demonstrated the ability of such systems to detect and discriminate between different ions. ${ }^{25,26}$ These findings opened the way of extensive sensing applications based on the so-called stochastic sensing, being the work of Bayley and co-workers considered as reference in this area. ${ }^{27}$ The selectivity of the system is given by specific receptors that can be inserted inside the nanochannel by genetic engineering techniques, allowing to detect a variety of analytes such as DNA, proteins and others, being the possibilities for DNA sequencing thoroughly studied ${ }^{28,29}$ as will be detailed in the following sections.

Solid-state nanochannels have emerged in the last years as alternative systems able to solve the drawbacks inherent to the biological ones, in terms of better stability, lower time of analysis, easier functionalization and precise pore-size control, representing reliable robust sensing platforms. ${ }^{30-32}$ Such solid-state nanochannels can be prepared following different methodologies, as will be detailed later. Some of these methodologies also allow to obtain nanochannel arrays, which have led to novel sensing systems both electrochemical $^{16}$ and optical. ${ }^{33-36}$ In this review we will focus only on the electrochemical approaches, as summarized at section 4 .

In the following sections an overview of the most representative and recent works related to the single-nanochannel resistive biosensing and the novel approaches developed for protein and DNA sensing using nanochannel arrays will be given. Electrical systems using single nanochannels are mostly based on the stochastic sensing, so they will be classified in this review in relation to the detected analyte. Nanochannel arrays-based sensing systems will be classified regarding the electrical technique used for the analyte detection. 


\section{ELECTRICAL BIOSENSING SYSTEMS BASED ON SINGLE NANOCHANNELS}

\subsection{Single nanochannel preparation}

As stated above, the most widely used biological nanochannel used for biosensing is the heptameric $\alpha$-hemolysin bacterial protein pore from Staphilococus aureus which consists of a transmembrane $\beta$-barrel and a big cap region sticking out. ${ }^{37}$ The nanochannel diameter in the entrances ranges from $2.9 \mathrm{~nm}$ (cis entrance) to $2 \mathrm{~nm}$ (trans entrance) while the internal cavity and the inner constriction measure $4.1 \mathrm{~nm}$ and $1.3 \mathrm{~nm}$ respectively. In a minor extent, porins such as $\mathrm{OmpG}^{38}$ and $\mathrm{MspA}^{39}$ have also been used as alternative to $\alpha$-hemolysin for the preparation of biological nanopores. Lipid bilayers where the biological ion channel is embedded are usually prepared across $30-100 \mu \mathrm{m}$ holes made in polymeric membranes such as polysulfone, Delrin or Teflon. ${ }^{40}$ The nanochannel is inserted by adding the protein solution to the as-prepared membranes. Support structures made of hydrogels ${ }^{41}$ or porous alumina ${ }^{42}$ between others have been used for improving the bilayer stability. Problems related to the lipid bilayer fragility can be solved using hybrid biological/solid-state ion channels prepared by inserting the protein channel in a synthetic material. ${ }^{11}$

Track-etching on polymeric membranes was the pioneer approach for the preparation of solid-state single nanochannels. ${ }^{43}$ However, most of nanochannels used nowadays for biosensing are prepared by drilling them on silicon nitride/silicon oxide membranes using electron-beam lithography, taking advantage of the high degree of pore-size control provided by commercial TEM/SEM instruments. ${ }^{44}$ Ion beam sculpting made by modern focused ion beam (FIB) machines equipped with an electron beam for imaging (called dual-beam or cross-beam machines $)^{45}$ allow to improve the accuracy of the sculpting. Emerging materials such as graphene, hafnium oxide, boron nitride and molybdenum 
disulphide have been recently proposed as alternative and advantageous materials for drilling single nanochannels, as will be detailed at section 3.3.

Details about preparation and characterization of single-nanochannels for biosensing applications have been reported in a recent review by our group. ${ }^{16}$

\subsection{Analytical applications of single nanochannels}

\subsubsection{DNA analysis and sequencing}

In the 90's was demonstrated for the first time that individual molecules of ssRNA and ssDNA could be driven electrophoretically through a single $\alpha$-hemolysin channel (Figure 2A) and consequently detected using the stochastic sensing principle. ${ }^{32}$ Covalent immobilization of ssDNA probe inside the protein nanochannel allows the DNA hybridization detection at single-base resolution by measuring changes in ionic current. $^{36,46}$ Biotin-streptavidin complexes and terminal hairpins have also inserted into the nanochannels for the ssDNA immobilization with the aim of improving the discrimination between current pulses coming from individual nucleotides. ${ }^{47,48}$

Although these pioneer and representative works were done using biological ion channels, most of the recent works for DNA analysis using nanochannels are based on robust solid-state ones, generated by electron-beam lithography/ion-beam sculpting in thin artificial membranes, being silicon nitride/oxide and aluminum oxide membranes the first and most popular ones used for this purpose. Changes in current during DNA translocation on these nanochannels can be used to identify sequences of individual DNA. ${ }^{49-56}$

A variation in the standard architecture of solid-state single nanochannel systems has recently been reported by Rant's group. ${ }^{57,58}$ The proposed device consists of two stacked 
nanopores separated by a micrometer-sized pyramidal compartment, the so-called "porecavitypore" (PCP). This architecture allows not only sensing but also analyte manipulation since it single particles or macromolecules can be electrophoretically trapped within the formed cavity and released upon demand applying a voltage pulse.

Single-molecule detection of specific sequences after DNA hybridization can also be carried out after immobilization of specific ssDNA ${ }^{59}$ or even peptide nucleic acid (PNA) probes $^{60}$ inside these nanochannels.

Probably the most exciting perspectives in the nanochannels-based electrical biosensing field are those related to the DNA sequencing possibilities, as first proposed by Kasianowicz and co-workers in $1996 .{ }^{61}$ They found that ssDNA (or RNA) could be electrophoretically driven through the $\alpha$-hemolysin pore and pass in an elongated conformation. Each of the four DNA bases (A,T,C and G) interacts in a specific way with the inner surface of the nanochannel, giving rise to "fingerprint" signatures (Figure 2B). Base composition and strand length affect the recorded current and the transit time while mutations in DNA modify the magnitude of conductance. This pioneer work opened the way to extensive research in this field as summarized in many reviews published in the last years. ${ }^{13,62-64}$ Reflection of the great potential of these sequencing systems for building fourth-generation methods alternative to traditional chain-termination and singlemolecule based ones in terms of time and cost of analysis are the commercial devices currently available (Figure 2C). ${ }^{65-67}$

In spite of such perspectives, important problems still limit the success implementation of nanochannels four routine DNA sequencing. One of the main limitations is related to the high speed of DNA translocation which avoids a good resolution in the signals coming from different nucleotides. In this context, recent efforts have focused in the tuning of 
nanopore wall surface charge so as to increase the residence time of each nucleotide inside the channel. ${ }^{68}$

The relative high noise in the ionic current recorded with biological channels is also an important problem for a single base resolution. With the aim of solving this, Farimani et al. have very recently proposed that not only ionic current but also tension can be measured for a more precise DNA sequencing, using mechanosensitive (MS) ion channels, ${ }^{69}$ which are able to transduce mechanical tension into an electrochemical response, as alternative to traditional $\alpha$-hemolysin ones.

\subsubsection{Protein detection}

The small size of the $\alpha$-hemolysin channel, which has a narrowest constriction of $1.4 \mathrm{~nm}$, represents a main limitation for big analytes translocation and subsequent detection. For example, most of proteins such as globular ones are not able to translocate in their folded native state, being necessary the use of specific ligands bound to the head of the pore which recognize the protein out of the channel. Proteins selectively captured in this way produce changes in the channel current, making possible their detection (Figure 3A). Polymers modified with biotin, ${ }^{70}$ disaccharides, ${ }^{71}$ inhibitor peptides ${ }^{72,73}$ and aptamers ${ }^{74}$ are probably the most representative examples of ligands used with this purpose, applied in these cases for streptavidin, lectins, protein kinases and thrombin detection respectively, as extensively studied by Bayleys's group. Alternatively, denaturation by chemical, ${ }^{75}$ thermal,${ }^{76}$ mechanical,${ }^{77}$ or enzymatic ${ }^{78}$ treatment for unfolding have allowed studies of protein translocation through $\alpha$-hemolysin nanochannels (Figure 3B).

As in the case of DNA, solid-state nanochannels have emerged as robust and improved sensing platforms for protein analysis. Furthermore, such artificial nanochannels can be prepared with arbitrary dimensions, permitting protein translocation in native folded 
state. ${ }^{79,80}$ However, recent efforts in the use of thin membranes and high bandwidth amplifiers haven`t been enough to solve the big challenge related to the poor resolution in the analysis of translocation events coming from proteins of similar size, ${ }^{81}$ being necessary the use of receptors to provide selectivity. As representative examples of these approaches can be considered the use of nitriloacetic acid receptors in silicon-nitride membranes (Figure 4C) $)^{82}$ and the introduction of metal-chelating ligands in polymeric membranes (Figure 4D) ${ }^{83}$ for His-tagged proteins and lactoferrin detection respectively, at levels of around $150 \mathrm{nM}$. dsLNA (locked nucleic acid) has also been connected to silicon nitride nanopores for the selective detection of Nuclear Factor-kappa B proteins. ${ }^{84}$ Recent efforts have been directed in the selective detection of proteins without modification of the solid-state nanopores, which usually requires important engineering processes. Of special relevance is the very recent work reported by Bell et al. ${ }^{85}$ in which the selectivity of the protein detection is given in solution. They designed a 200-mer dsDNA with chemical motifs at tailored positions for binding of protein molecules of interest. Captured proteins in solution produce changes in the DNA signatures, allowing in this case the selective streptavidin detection at pM levels.

\subsubsection{Viruses and toxins detection}

Nature mechanisms are also approached for virus detection using biological ion channels. It is known that translocation of the viral DNA into host cytoplasm occurs after bacteriophage docking to specific receptors in the bacterial membrane, being the bacteriophage lambda $(\lambda)$ virus and the maltoporin $(\mathrm{LamB})$ receptor a well-known couple. ${ }^{86}$ Taking advantage of this natural behaviour, Bezrukov's group mimicked this system for the detection of $\lambda$ virus particles using LamB ion channel. ${ }^{87}$ 
A variety of spherical and icosahedral virus strains have also been detected using solidstate nanopores with suitable dimensions. ${ }^{88-90}$ Very recently, Stein and co-workers ${ }^{91}$ studied for the first time the mechanisms affecting the translocation of a filamentous virus through silicon nitride membranes, concluding that the stiffness of such kind of virus avoid hernias formation which make them able to pass through the channels only in elongated forms. This coupled with the long length of the virus (around $1 \mu \mathrm{m}$ ) generates well resolved/easy-to-read signatures, opening the way to reliable future label-free virus detection systems (Figure 4A).

Regarding toxins, Martin's group efforts for ricin (a potent cytotoxin from the castor bean plant) detection using gold-modified solid-state nanochannels in polymeric membranes must be highlighted. ${ }^{92}$ Gold deposition inside the channels allow to easily control the channel diameter so as to adapt it to the size of the analyte (in this case to $4 \mathrm{~nm}$ ) as well as facilitates receptors immobilization. Antibodies anti-ricin are immobilised inside channels through streptavidin-biotin interactions, being able to detect the blocking in the channels for ricin concentrations of $100 \mathrm{nM}$.

In addition to the use of specific antibodies, small toxins can also be detected by monitoring the toxin's enzymatic activity on its substrate. This is the strategy very recently followed by Wang et al. for botulinum neurotoxins (BoNTs) (the most lethal toxins to human) detection using biological nanochannels. ${ }^{93}$ The cleavage products generated in a proteins substrate by the action of the toxin produce specific current blocks that allow to identify subnanomolar levels of toxin within minutes (Figure 4B).

\subsubsection{Detection of non- biological molecules}


Although this review is focused on the use of nanochannels for biological molecules detection, it must be mentioned that single-nanochannels, both biological and synthetic, have also been applied for the detection of a variety of non-biological analytes. Chemical (organoarsenic compounds, nitrogen mustards and organophosphorus nerve agents), and explosive (2,4,6-trinitrotoluene and liquid explosives) agents, as rightly reviewed by Liu et $\mathrm{al}^{94}$ have been detected using nanochannels.

Bayley's group also pioneered the detection of divalent metal ions using the $\alpha$-hemolysin nanochannel. ${ }^{95}$ Mercury (II) ions have been recently detected with a high degree of sensitivity and selectivity taking advantage of the well-known coordination-based interaction between such ions and bisthymine. ${ }^{96}$ The mercury (II)-mediated duplex formed in a specifically designed ssDNA generates a stable hairpin structure, which significantly changes the translocation signature of the ssDNA, allowing to detect levels of $7 \mathrm{nM}$ these ions.

Finally, it deserves mentioning that in addition to detection of a wide range of analytes, single-nanochannels can also be used to measure the function and viability of biological molecules. Enzymatic cleavage and protein unfolding processes are the most representative examples of biological processes successfully monitored using these approaches, as extensively reviewed by Kasianowicz's group. ${ }^{10}$

\subsection{Emerging materials: graphene, hafnium oxide, boron nitride and molybdenum disulfide}

Within the solid-state nanopore family, graphene has recently gained considerable attention as alternative to traditional silicon nitride/silicon oxide based membranes. Graphene atomically thin membrane with vast electrical and mechanical properties ${ }^{97,98}$ is 
also an ideal substrate for sculpting thin nanopores atom by atom ${ }^{99,100}$ making it a promising material for a new generation of nanopore-based sensing systems. Golovchenko's work can be considered as reference in the use of this material for drilling nanopores and detecting DNA translocation. ${ }^{101}$ Graphene nanoribbons have also been used as transistors integrated with nanopores for DNA translocation detection by measuring modulations in tunnelling current (Figure 5A). ${ }^{102}$

Similar approaches have been reported using thin Hafnium oxide $\left(\mathrm{HfO}_{2}\right)$ membranes, taking advantages of the excellent properties of this material for building transistors (Figure 5B). ${ }^{103}$

Simulations of the interaction of graphene-based nanochannels with the four DNA bases (ATCG) have also been reported, as shown at section 3.2 focused on DNA sequencing.

In spite of its advantages, the use of graphene is limited here by the unspecific adsorption of DNA through the strong $\pi-\pi$ interaction, ${ }^{104}$ which may difficult the translocation.

In this context, Boron nitride (BN), also known as "white graphene", has also been proposed to be used as alternative 2D material for drilling nanopores with biosensing purposes. This material has analogous properties to graphene due to a similar crystal structure but with alternated $\mathrm{B}$ and $\mathrm{N}$ atoms, ${ }^{105}$ having a single layer $\mathrm{f} \mathrm{BN}$ a thickness that is similar to the spacing between bases in ssDNA $(0.32-0.52 \mathrm{~nm}),{ }^{106}$ making it an outstanding material for single-base DNA resolution (Figure 5C). ${ }^{107}$

With the same aim, Molybdenum disulfide $\left(\mathrm{MoS}_{2}\right)$, a material complementary to graphene due to its semiconductive nature and other interesting physical properties, has also been very recently proposed by Radenovic's group as an inorganic analogue of graphene for building very thin nanopores applied for DNA translocation detection (Figure 5D). ${ }^{108,109}$ 
Recent studies point to the use of solid-state nanochannels drilled in graphene as advantageous platforms for DNA sequencing, taking advantage of the properties of this material detailed in the previous section. Graphene nanochannels on silicon nitride membranes have been used for this purpose ${ }^{110,111}$ while very recent theoretical studies/simulations have explored the potential of bilayer graphene as next generation platform for DNA sequencing. ${ }^{112-114}$ Emerging materials like boron nitride and molybdenum disulphide are expected to play an important role in this field.

Finally, in addition to graphene and its analogues, it deserves to be mentioned that nanoporous gold prepared by dissolution of silver from a silver/gold alloy has also been used for DNA hybridization detection. ${ }^{115,116}$

\section{ELECTRICAL BIOSENSING SYSTEMS BASED ON NANOCHANNEL} ARRAYS

\subsection{Nanochannel arrays preparation and functionalization}

The most common routes followed for the preparation of nanochannel arrays are i) metallic substrate anodization, ii) micro/nanomolding and iii) high ordered mesoporous thin films formation.

The most popular nanochannel arrays, widely used in a variety of applications, are those consisting in anodic aluminum oxide (AAO) nanoporous membranes. ${ }^{117}$ AAO membranes are typically prepared by anodization of highly pure aluminum, followed by acidic dissolution, resulting in the nanochannels formation (Figure 6A). ${ }^{118-120}$ AAO nanochannels can also be directly generated on an electrotransducer surface which is of great interest for biosensing applications. ${ }^{121}$ Furthermore, AAO membranes are rich in hydroxyl groups, which allow their easy functionalization, typically after silanization and later modification with binding ligands. ${ }^{122}$ 
Nanochannel arrays on solid substrates can also be built by highly ordered mesoporous thin film coatings, being the use of self-assembled nanoparticle templates ${ }^{123}$ and of hard templating/nanocasting approaches ${ }^{124}$ the most typical preparation routes (Figure 6B). ${ }^{125}$ The self-assembly of polystyrene nanospheres to create nanostructured surfaces on transparent conductive oxide (TCO) substrates deserves to be highlighted as highly advantageous for electrochemical/optical sensing systems. ${ }^{126,127}$ The use of i.e. carboxylmodified nanospheres allows their easy functionalization for further biosensing applications.

Finally, micro/nanomolding techniques are also suitable for the preparation of nanoporous membranes on solid substrates. Micro/nanomolding using both the traditional $\mathrm{PDMS}^{128}$ and the emerging block copolymers ${ }^{129}$ has been proposed for such purpose. Recent advances in nanoimprint lithography (NIL) have allowed to solve problems related to film delamination and breaking, leading to 3D nanochannels preparation on flexible substrates with high potential for mass production (Figure 6C). ${ }^{130}$ Functionalization of such nanoporous polymeric membranes can be done by ammonia plasma which introduces amino groups.

\subsection{Impedimetric, capacitive, conductometric and resistive sensing systems}

\subsubsection{DNA, protein, and bacteria detection using AAO nanoporous membranes}

Electrochemical impedance spectroscopy (EIS), conductivity, resistivity and capacitance measurements on electrodes modified with AAO nanoporous membranes have been used in the last years for the detection of a variety of analytes. ${ }^{15}$

EIS is an ideal detection technique on AAO membranes, since the electrical characteristics of AAO can be easy adjusted to an equivalent circuit. Changes in impedance or conductance produced by biorecognition reactions in the inner walls of the 
nanochannels consequently allow to detect the analyte of interest. Smirnov's group was the pioneer in the application of these principles for the detection of DNA hybridization ${ }^{131,132}$ followed by others who recently worked in i.e. the integration of AAO membranes in chips (Figure 7). ${ }^{133}$ This kind of approach has been recently proposed for the detection of ssDNA related to analytes of interest in diagnostics, such as Dengue virus at levels of $\mathrm{pM}$, allowing to discriminate even single base mismatches. ${ }^{134}$

AuNP tags and silver amplification have also been recently proposed for the improvement of the performance of these DNA sensing systems ${ }^{135}$ reaching LODs of $50 \mathrm{pM}$ for 25 mer ssDNA.

Proteins have also been detected following this sensing format. Biotin, as model analyte, has been detected in studies focused on the exploration of the influence of AAO nanochannel dimensions on non-faradic EIS, ${ }^{136}$ obtaining important information for further developments in this field.

Foodborne pathogens such as Escherichia coli O157:H7 and Staphylococcus aureus have also been evaluated based on the same principles, reaching detection limits as low as $10^{2}$ CFU/mL with high specificity. ${ }^{137}$

Enzymatic processes have also been monitored using AAO nanoporous membranes and impedimetric detection. That is the case of the enzymatic activity of botulinum neurotoxin A that has been recently evaluated by Ye and co-workers ${ }^{138}$ by measuring the cleavage activity through impedance signals, reaching detection limits of $500 \mathrm{pM}$ of a light chain protease. Urease activity has also been evaluated by conductometric measurements. ${ }^{139}$

Recent efforts have focused on the improvement of the gating efficiency of such systems, using i.e. a so-called supersandwich formed by a capture probe ssDNA immobilized on the AAO nanochannels hybridized with two target ssDNA strands, one of them being an 
aptamer for analyte (adenosine triphosphate, ATP) recognition (Figure 8). ${ }^{140}$ The supersandwich keeps the channel closed with a perfect electric seal in the absence of analyte. The reversible disassembly through ATP-DNA binding interactions (closed-toopen) exhibits high ON-OFF rations, considerably higher than the obtained with chemically modified nanofluidic systems, allowing to achieve the IMPLICATION logic operations within the nanofluidic structures.

\subsubsection{AAO nanoporous membranes as gas sensing platforms}

AAO nanoporous membranes have high affinity to adsorb gases and vapours. This property, together with their high surface area and resistance to high temperatures make them ideal platforms for gas sensing. Relative humidity $(\mathrm{RH})$ capacitance sensors on AAO membranes have been proposed by Juhász and co-workers ${ }^{141}$ reaching a performance much better than the obtained with commercially available humidity sensors in terms of sensitivity and simplicity.

Important environmental contaminants such as nitrogen dioxide, ammonia, ethanol have been detected in resistive sensors using $\mathrm{WO}_{3}$ thin films deposited on AAO membrane templates. ${ }^{142}$ The tungsten oxide gas sensing structures supported by AAO templates showed high responsiveness to the above mentioned substances, especially to nitrogen dioxide which is detected at 1 ppm levels. Polychlorinated biphenyls (PCBs) have also been evaluated in capacitive biosensors on bare AAO membranes (Figure 9) ${ }^{143}$ at nM levels, showing advantages of easier operation, faster detection and higher sensitivity compared to conventional PCBs detectors.

\subsection{New trends: voltammetric sensing combined with the use of nanoparticles}




\subsubsection{Protein and DNA detection using AAO nanoporous membranes}

The use of nanoporous membranes as modifiers of electrotransducer surfaces has been recently proposed for voltammetric biosensing of proteins and ssDNA. AAO nanoporous membranes have been extensively used for this purpose, detecting and quantifying the analyte in the sample by measuring the nanochannel blocking produced by the biorecognition reaction (immunocomplex or DNA duplex formation). This behaviour is consistent with the pore size of the AAO membrane used (typically 200 and $20 \mathrm{~nm}$ ) and the size of both antibody and antigen $(14.5 \mathrm{~nm} \times 8.5 \mathrm{~nm} \times 4 \mathrm{~nm}$ for human immunoglobulin $\mathrm{G}(\mathrm{HIgG})$ ) and of an i.e. 21-mer ssDNA (diameter of $1.84 \mathrm{~nm}$ and length of $0.38 \mathrm{~nm}$ ). The blocking in the nanochannel is evaluated by the decrease in the voltammetric signal of a standard red-ox indicator, as illustrated in Figure 10A. ${ }^{144,145}$ The cell set-up (Figure 10B) consists in fixing the nanoporous membrane onto a screenprinted carbon electrode (SPCE) by physical attachment, between two methacrylate blocks which define the electrochemical cell for the voltammetric measurement in the $\left[\mathrm{Fe}(\mathrm{CN})_{6}\right]^{4-} /\left[\mathrm{Fe}(\mathrm{CN})_{6}\right]^{3-}$ system.

With the aim of improving the limits of detection (LOD) of the label-free assays (LOD: $5 \mu \mathrm{g} / \mu \mathrm{L}$ for a 21 -mer ssDNA and $100 \mu \mathrm{g} / \mathrm{mL}$ for HIgG) two amplification strategies have been proposed. The first strategy is based on the use of $80 \mathrm{~nm}$-sized gold nanoparticle (AuNP) tags in sandwich assays following by silver deposition for increasing the nanochannel blocking (Figure 10C). ${ }^{146}$ The second approach consists in changing the standard redox indicator by $4 \mathrm{~nm}$-sized Prussian Blue nanoparticles (PBNPs), which bigger size produces a higher hindering in their diffusion through the channels to the electrode by lower amounts of analyte. ${ }^{147}$

Furthermore, AAO nanoporous membranes have been used not only as sensing platforms but also as filters of big-sized interferences in real samples (i.e. blood cells), allowing to 
minimize matrix effects (Figure 11) ${ }^{146,148}$. This has been approached for the detection of biomarkers in complex matrixes such as whole human blood and cell cultures at clinical relevant levels (i.e. $50 \mathrm{ng} / \mathrm{mL}$ for HIgG and PTHrP; $52 \mathrm{U} / \mathrm{mL}$ for CA15-3; $1.8 \mathrm{ng} / \mathrm{mL}$ for thrombin). The same principle has been applied for the detection of DNA hybridization reaching LODs of $42 \mathrm{ng} / \mu \mathrm{L}$ for a 21 -mer ssDNA. ${ }^{145}$

\subsubsection{Protein detection using nanochannels created by self-assembled nanospheres}

In spite of their excellent performance, AAO nanoporous membranes based sensing systems suffer from two important limitations. First, they are not integrated systems since a rather time consuming / not user friendly set-up is necessary for fixing the membrane onto the electrode surface. Furthermore, the micrometric thickness of the AAO membranes is probably the main responsible of the poor sensitivity of the label-free assays which make necessary amplification strategies. In this context, thin nanochannels directly created onto the electrotransducer surface would be an ideal alternative to overcome such limitations.

In this direction, a nanoparticles-based nanochannel platform assembled onto a flexible substrate has been very recently proposed. ${ }^{149}$ This platform is formed by dip-coating of a monolayer of self-assembled carboxylated polystyrene nanospheres (of $200 \mathrm{~nm}$ and 500 $\mathrm{nm}$ in diameter) onto the working area of a hybrid screen-printed ITO/PET electrode (Figure 12A-C). The interstitial spaces between the nanospheres generate nanochannels of around 65 and $24 \mathrm{~nm}$ for the $200 \mathrm{~nm}$ and $500 \mathrm{~nm}$-sized spheres respectively, being these used for the detection of proteins, taking advantage of the same sensing principle described in the case of the AAO membranes (Figure 12D). This system shows nanochannel-size dependency and is applied for the detection of HIgG at levels of 580 $\mathrm{ng} / \mathrm{mL}$ in human urine samples with an excellent specificity (Figure 12E-F), opening the 
way to fully integrated nanochannels-based sensing systems for point-of-care applications.

\section{CONCLUSIONS AND PERSPECTIVES}

Nanochannels are emerging platforms with outstanding potential for a variety of electrical biosensing applications. Inspired by the Coulter microparticle counter, the use of biological single nanochannels inserted in lipid bilayers, mimicking the mechanism of action of the pore forming toxins, have opened the way to an extensive research in this field. DNA, proteins, viruses and toxins are some of the analytes that have been detected by measuring conductance changes produced by the analyte translocation through the nanochannel. Of special relevance are the exciting perspectives related to the use of these sensing systems for a new generation of DNA sequencing devices, being some prototypes commercially available.

Solid-state single nanochannels mainly prepared by drilling nanopores on silicon nitride/silicon oxide membranes by electron-beam lithography using TEM/SEM instruments are nowadays implemented as alternative to the biological ones in terms of robustness, stability, easy functionalization and pore-size control. In this context, materials such as graphene, molybdenum disulphide, boron nitride and hafnium oxide have emerged in the last years as advantageous platforms for drilling nanopores, opening great prospects for future implementation, replacing silicon based materials.

Recent advances in the technology of preparation of nanochannels arrays, mainly by metallic substrate anodization, micro/nanomolding high ordered mesoporous thin films formation have opened the way to novel and versatile electrical biosensing systems. Anodized aluminum oxide (AAO) nanoporous membranes are the most used materials, due to well-known advantages related to easy functionalization and mass production 
possibilities, between others. The nanochannels blocking by the biorecognition reaction, typically immunocomplex or DNA duplex formation in the inner walls of the channels, allows to detect the biomolecule of interest taking advantage of voltammetric, impedimetric, conductometric, capacitive or resistive meaurements. These nanochannel arrays have been proposed as excellent filtering/sensing platforms for the analysis of human blood samples with low matrix effects and also for gas sensing, between other applications, representing reliable advantageous alternatives for point-of-care biosensing. Recent innovative approaches based on single-use assembled nanoparticles-based nanochannels onto flexible substrates are promising alternatives to AAO-based sensing systems in terms of integration and sensitivity. Great prospects in this field are focused on the use of nanoimprinting technologies (i.e., roll-to-roll printing) as well as other fabrication methodologies and novel nanomaterials for the preparation a novel generation of really integrated and one-step electrical biosensing systems for point-of-care applications. Either post-printing of nanopore/nanochannels (i.e. by self aassembling of nano/microparticles) onto electrical transducing platforms or development of already integrated nanopore/nanochanels-based conducting layers would bring new opportunities for real samples analysis/applications of this innovative and advantageous technology in various bioanalytical approaches.

\section{ACKNOWLEDGEMENTS}

We acknowledge the support of the Spanish MINECO under Project MAT2014-52485-P and through the Severo Ochoa Centers of Excellence Program under Grant SEV-20130295. The support from Secretaria d'Universitats i Recerca del Departament d'Economia i Coneixement de la Generalitat de Catalunya (Grant 2014 SGR 260) and from the E.C. under FP7-OCEAN 2013.1 contract number 613844 "SMS" are also acknowledged. 


\section{FIGURES}
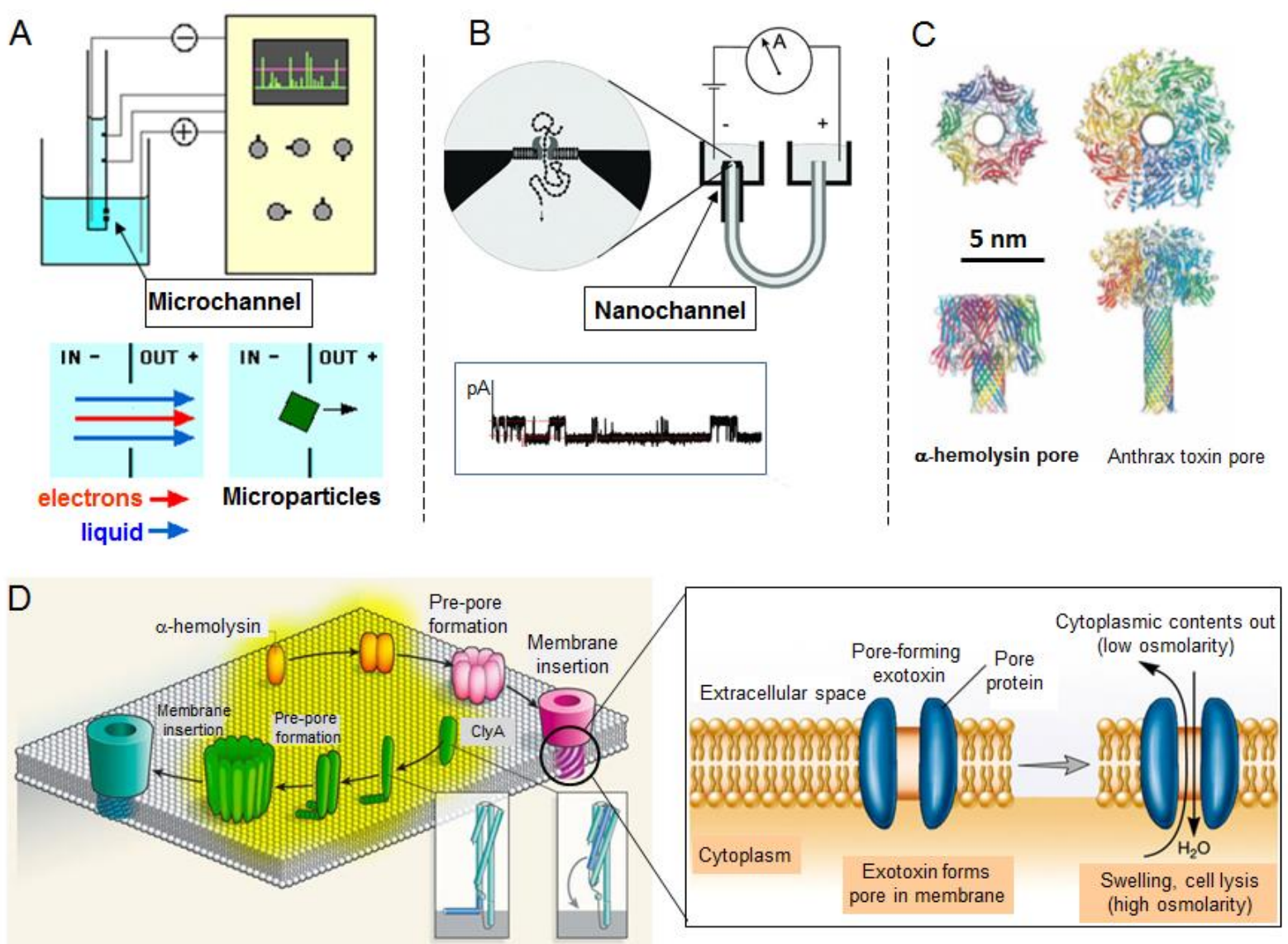

Figure 1. From the Coulter counter to the stochastic sensing. Scheme of a Coulter counter (A) and of its evolution to a nanochannel sensor (B). Adapted with permission from ref. 23. (C) Structure of the main protein ion channels used for the preparation of single nanopores for biosensing. Adapted with permission from ref. 13. (D) Scheme of the mechanism of action of pore forming toxins on cell membranes. Adapted with permission from ref. 21. 

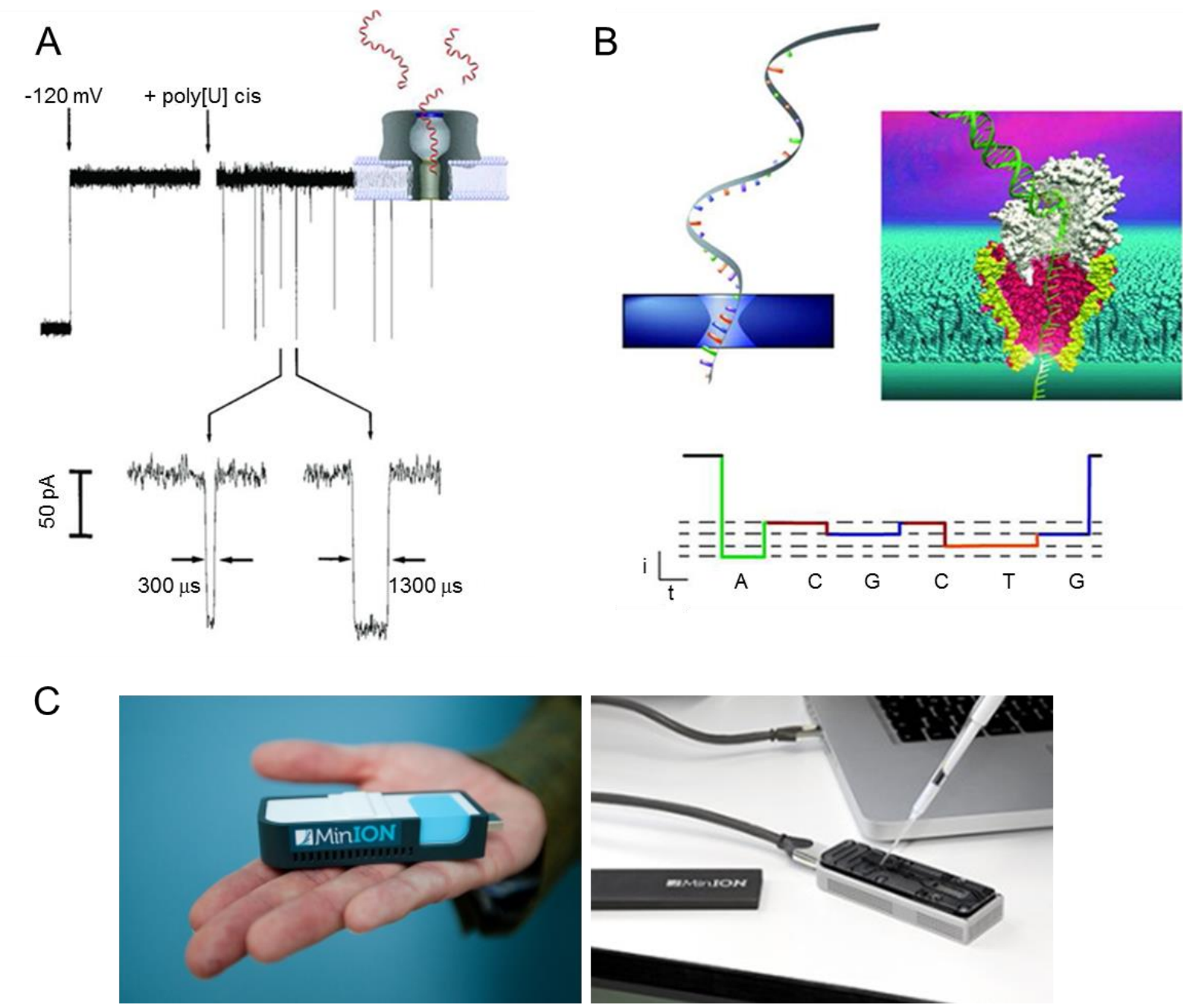

Figure 2. DNA analysis and sequencing using single nanochannels. (A) Scheme of the ssDNA translocation through a single $\alpha$-hemolysin pore and the associated electrical signatures. Adapted with permission for ref. 32. (B) $\alpha$-hemolysin pore as potential tool for DNA sequencing. ssDNA strand enters through the pore and each of the four bases produce characteristic time series recordings. Adapted with permission from ref 61. (C) Commercial devices proposed for DNA sequencing based on single nanochannels. Reproduced with permission of Oxford Nanopore Technologies Ltd. All rights reserved. 

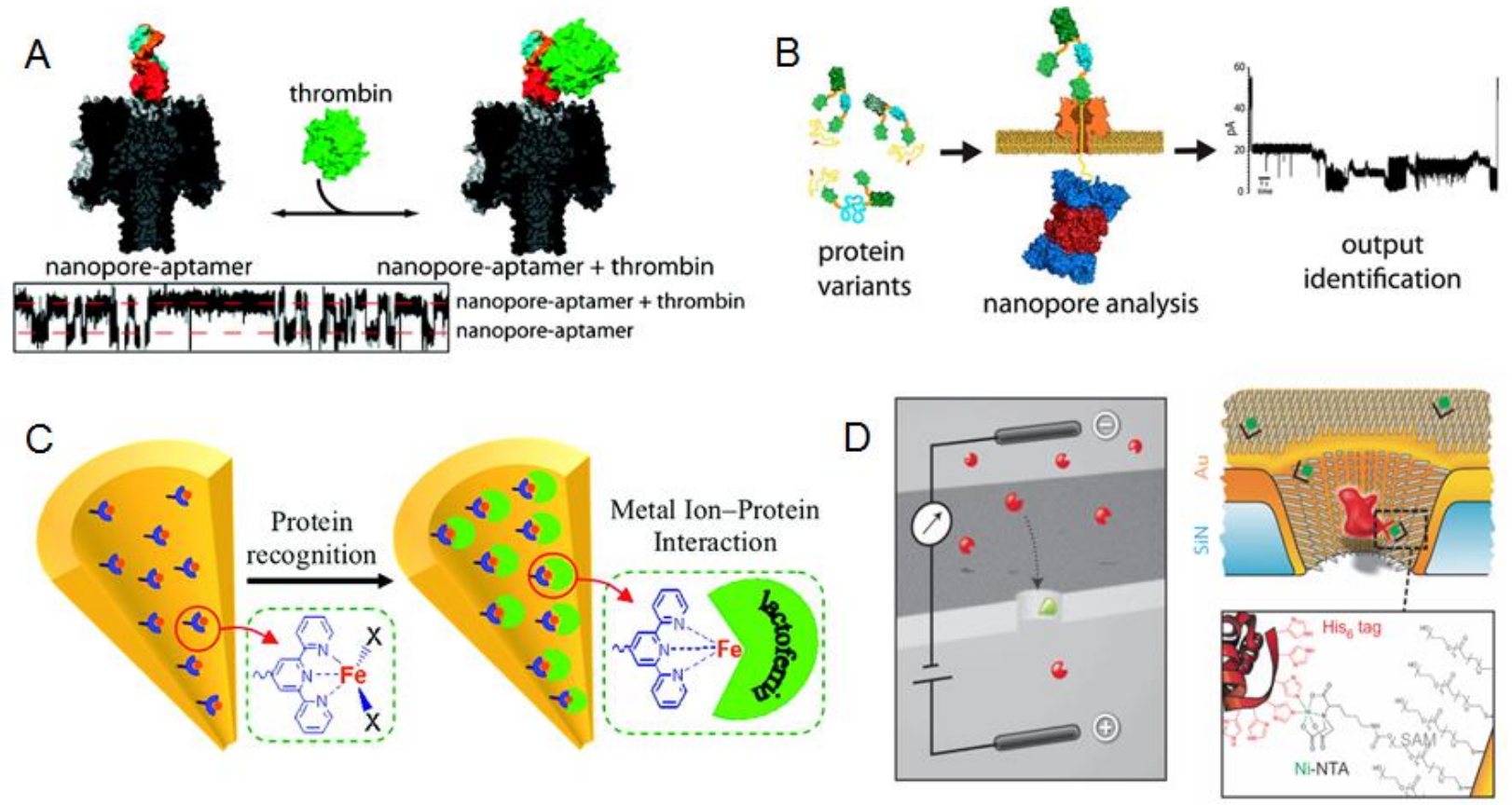

Figure 3. Different strategies for protein detection using single nanochannels. (A) Use of specific ligands bound to the head of the pore for protein recognition. Adapted with permission from ref. 74. (B) Protein denaturation for unfolding before translocation. Adapted with permission from ref. 78. (C) Use of nitriloacetic acid receptors in siliconnitride membranes. Adapted with permission from ref. 82. (D) Introduction of metalchelating ligands in polymeric membranes. Adapted with permission from ref. 83 . 

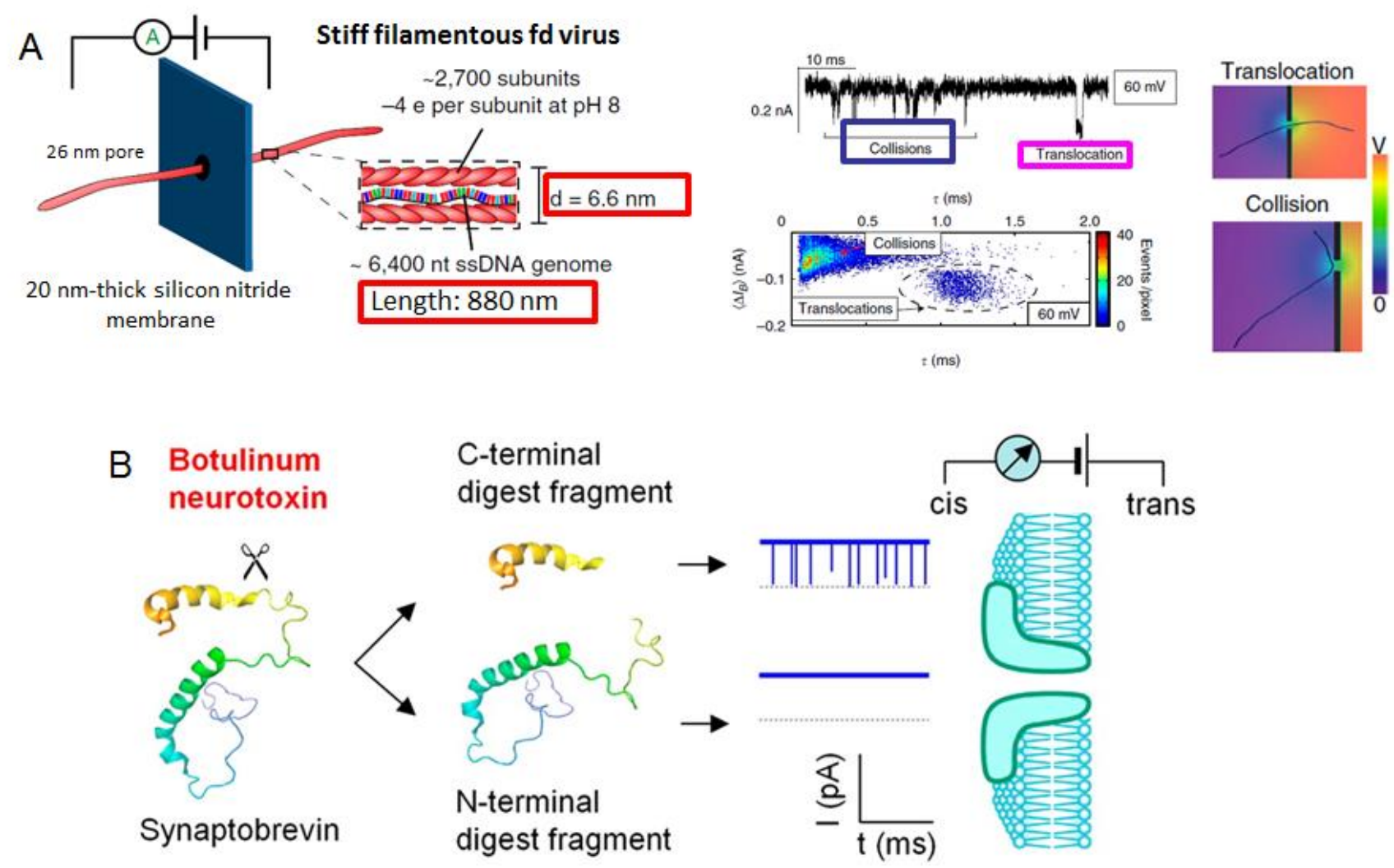

Figure 4. Virus and toxin detection using single nanochannels. (A) Filamentous virus translocation through silicon nitride membranes (left) and its well resolved/easy-to-read signatures discriminated from collisions (right) Adapted with permission from ref. 91. (B) Botulinum neurotoxins (BoNTs) detection by monitoring the toxin's enzymatic activity on its substrate. Cleavage products produce specific current blocks. Adapted with permission from ref. 93. 


\section{A}
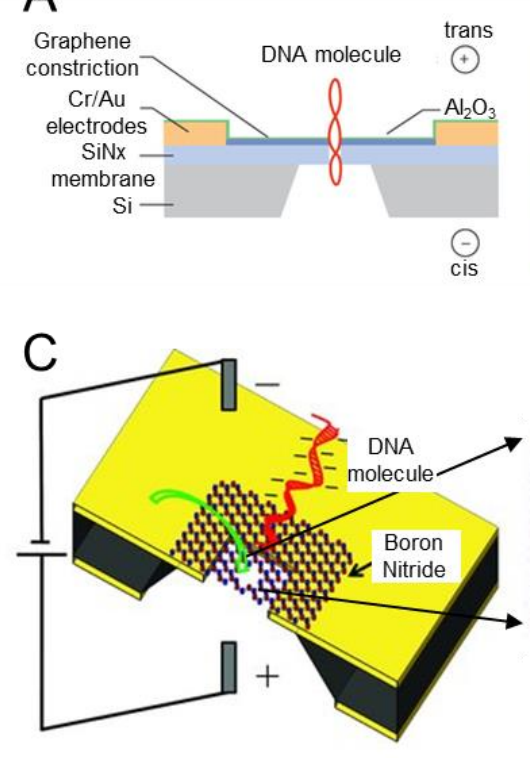

B

$\mathrm{Al}_{2} \mathrm{O}_{3} / \mathrm{Si}_{3} \mathrm{~N}_{4} / \mathrm{Al}_{2} \mathrm{O}_{3}(50 \mathrm{~nm} / 200 \mathrm{~nm} / 50 \mathrm{~nm})$

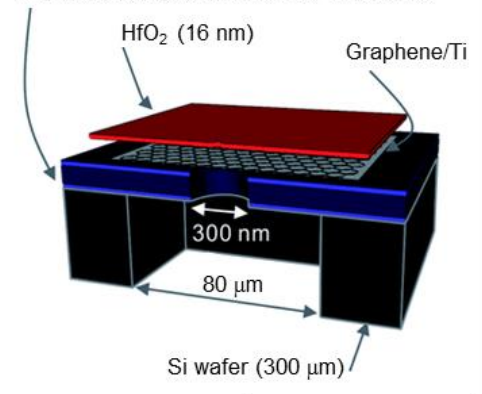

Figure 5. Emerging materials used for solid-state single nanochannels preparation: application for DNA analysis. Scheme of DNA systems based on nanopores drilled on thin membranes of graphene $(\mathbf{A})$, hafnium oxide $(\mathbf{B})$, boron nitride $(\mathbf{C})$ and molybdenum disulfide (D). Adapted with permission from refs. 102, 103, 107 and 108 respectively. 


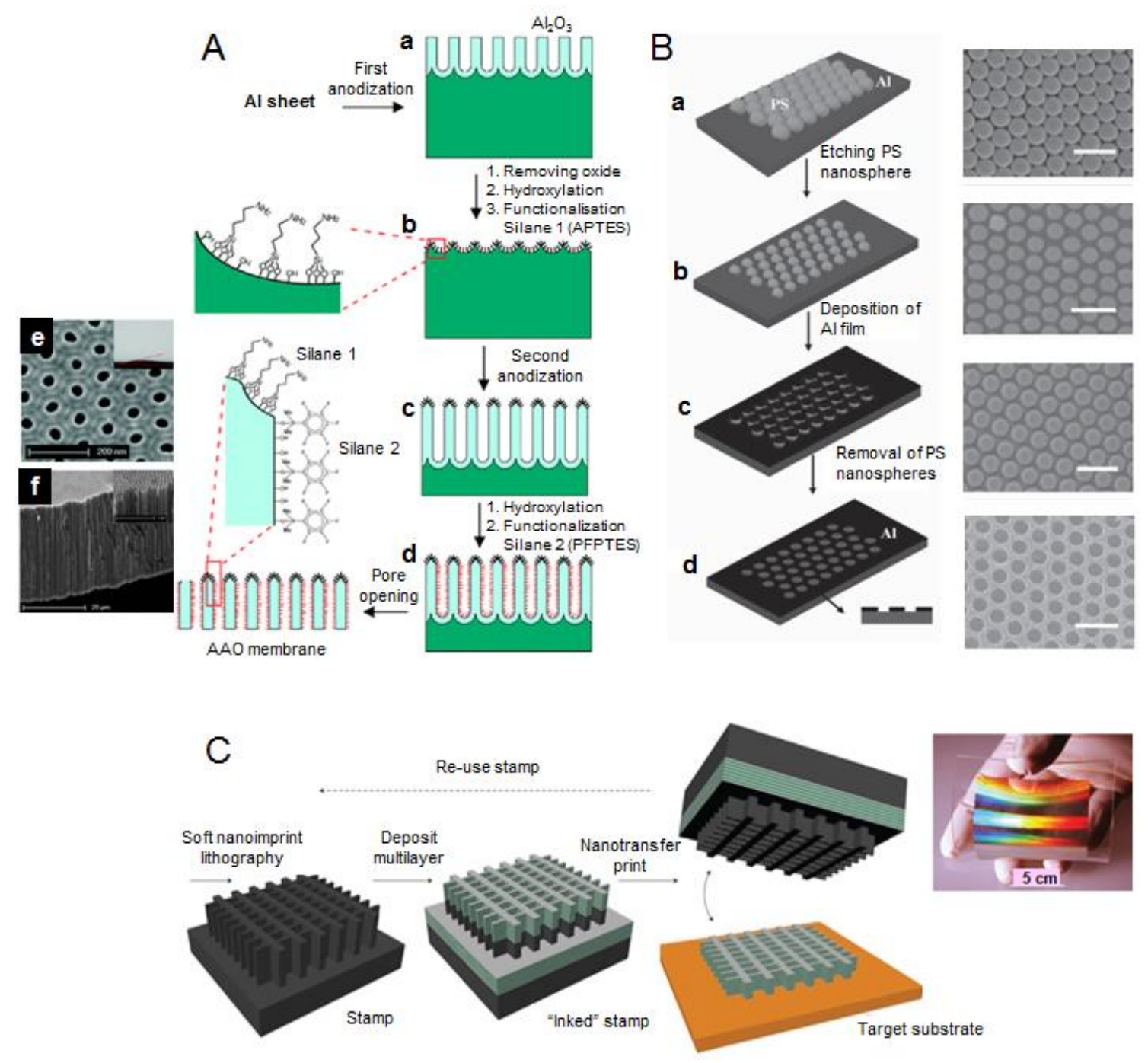

Figure 6. Nanochannel arrays preparation routes for biosensing applications. (A) Stepwise preparation of anodic aluminum oxide (AAO) nanoporous membranes by metallic substrates anodization. Adapted with permission from ref.120. (B) Schematic diagrams and corresponding SEM images of the nanochannel formation by nanosphere lithography on a solid substrate. The scale bars are $1 \mu \mathrm{m}$. Adapted with permission from ref 125 . (C) Schematics for the formation of well-oriented cylinders with perpendicular morphology for PS-PDMS thin films. Adapted with permission from ref 130. 

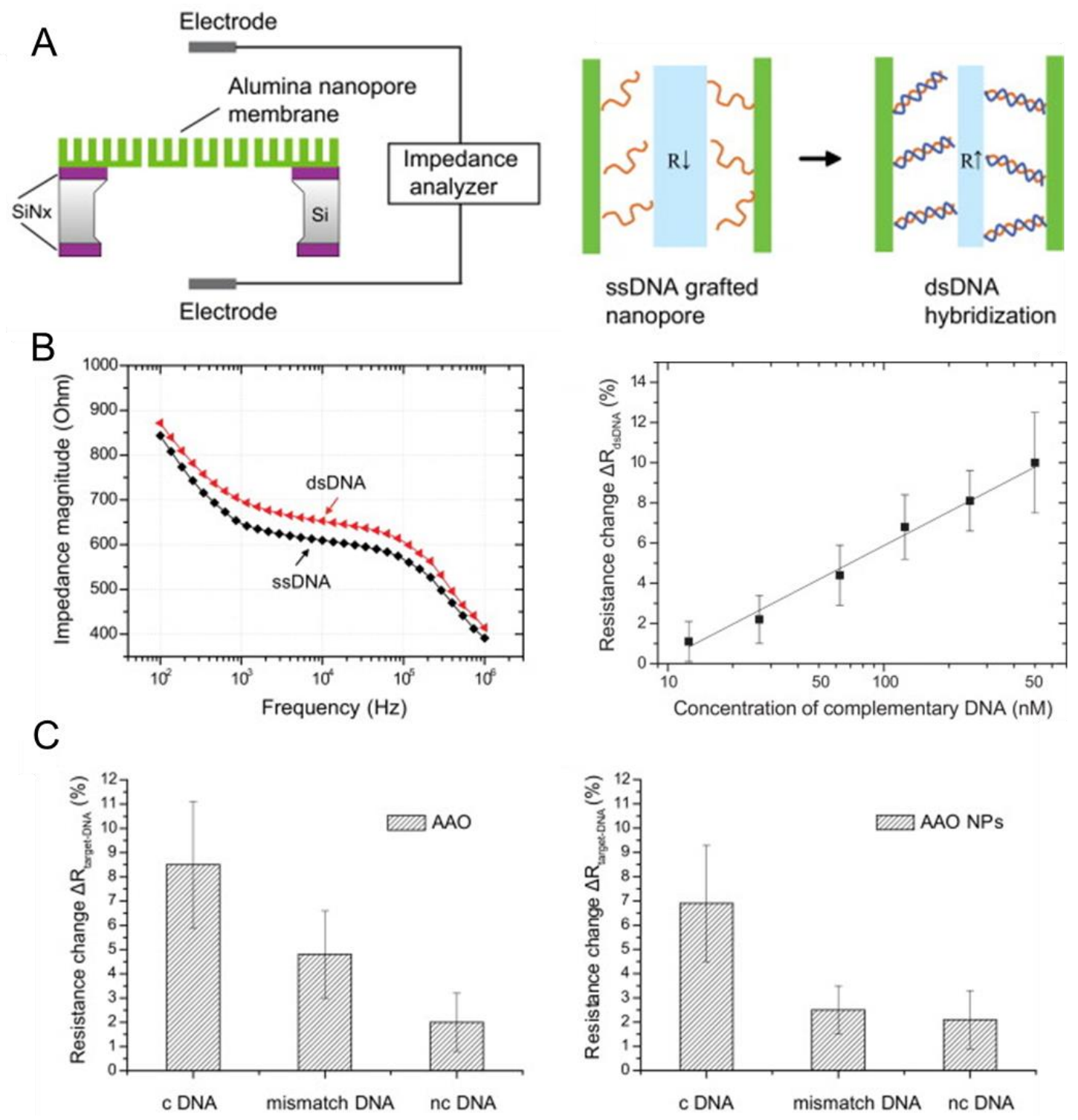

Figure 7. DNA impedimetric detction using AAO nanoporous membranes. (A) (Left) Schematic of a impedimetric DNA sensor. The nanoporous membrane is sandwiched between two half cells where a pair of $\mathrm{Ag} / \mathrm{AgCl}$ electrodes are inserted and connected to an impedance analyzer; (Right) Schematic of impedance increase due to the blocking of nanopores after dsDNA hybridization. (B) (Left) Impedance change of an ssDNA grafted alumina membrane after hybridization of double-stranded DNA (dsDNA, 25 bases); (Right) Plot of resistance change values during dsDNA hybridization versus the logarithm of complementary DNA concentrations. (C) Summary of membrane resistance increase in sensing various target DNA oligomers including complementary DNA (c DNA), 2 base pair mismatched DNA (mismatch DNA) and non-complementary DNA (nc DNA). (Left) is the summary for alumina membranes and (right) for silica nanoparticle coated alumina membranes. Adapted with permission from ref.133. 

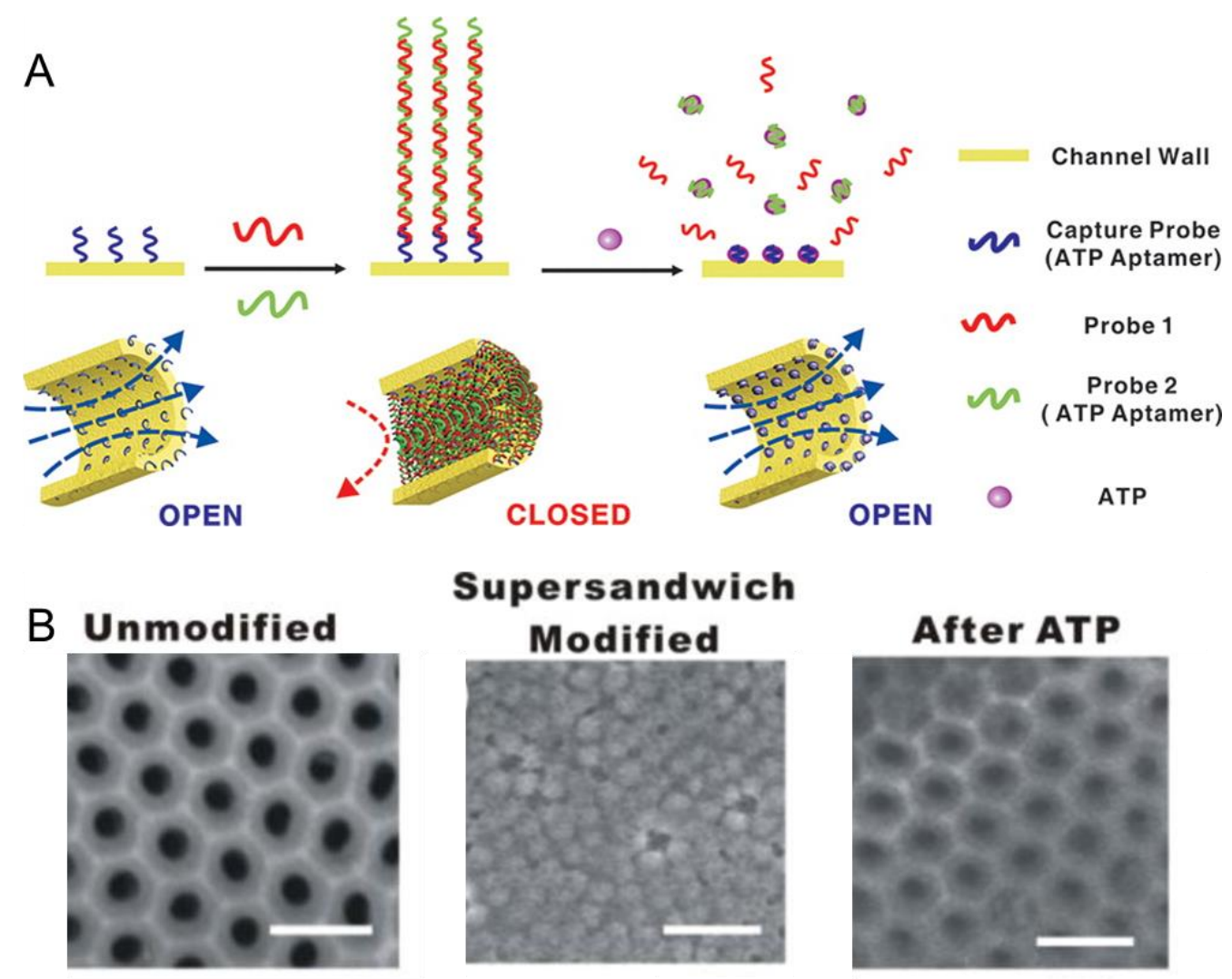

\section{Supersandwich}

\section{Modified}

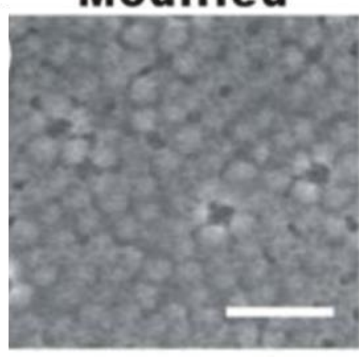

After ATP

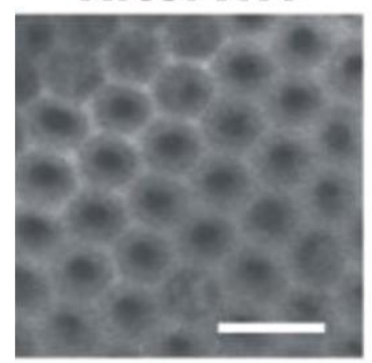

C
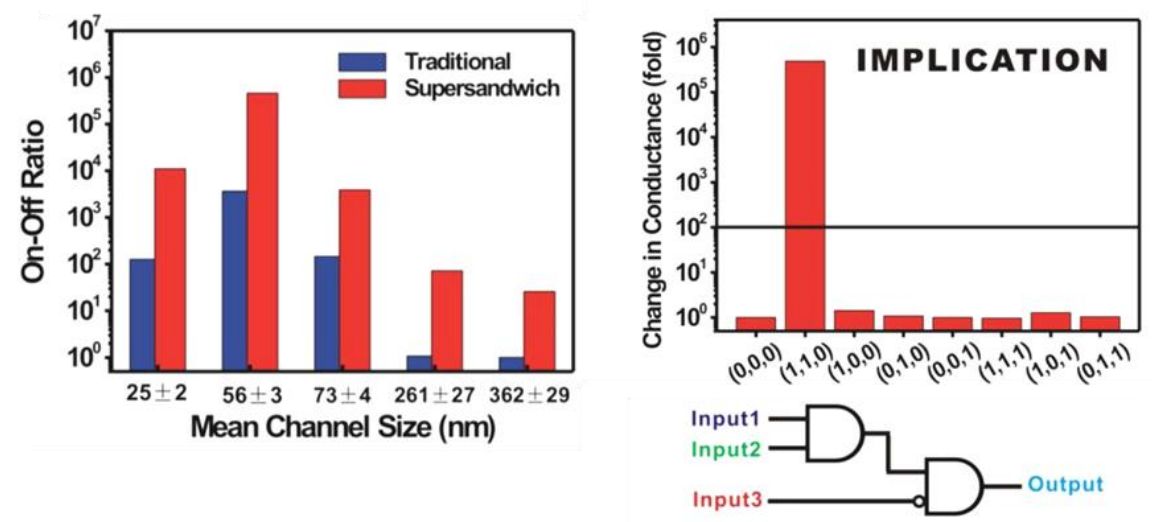

Figure 8. Improvement of the gating efficiency in conductometric sensors on nanoporous membranes. (A) Scheme of the gating of AAO nanochannels by DNA supersandwich assemblies and ATP. (B) SEM characterizations of the DNA assembly and disassembly on the membrane surface for unmodified, supersandwich modified and after ATP recognition. (C) (Left) Comparison of $\mathrm{ON}-\mathrm{OFF}$ ratios for a standard system and for the proposed supersandwich; (Right) Operations of the three-input IMPLICATION nanofluidic logic device and symbolic expression. Adapted with permission from ref. 140. 


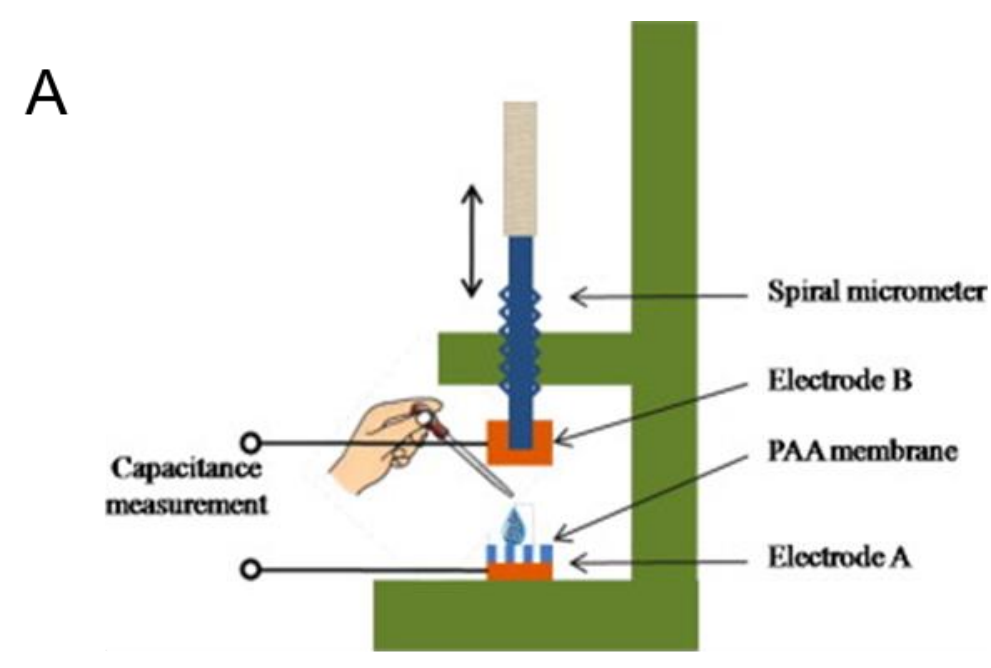

B

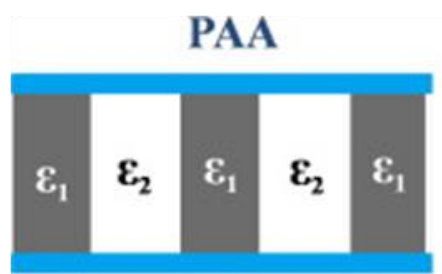

a

$\mathrm{PAA}+\mathrm{PCB}, \varepsilon_{3}$

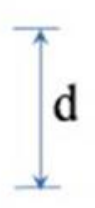

b

alumina

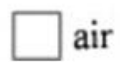

$\therefore$ PCB

electrode

C
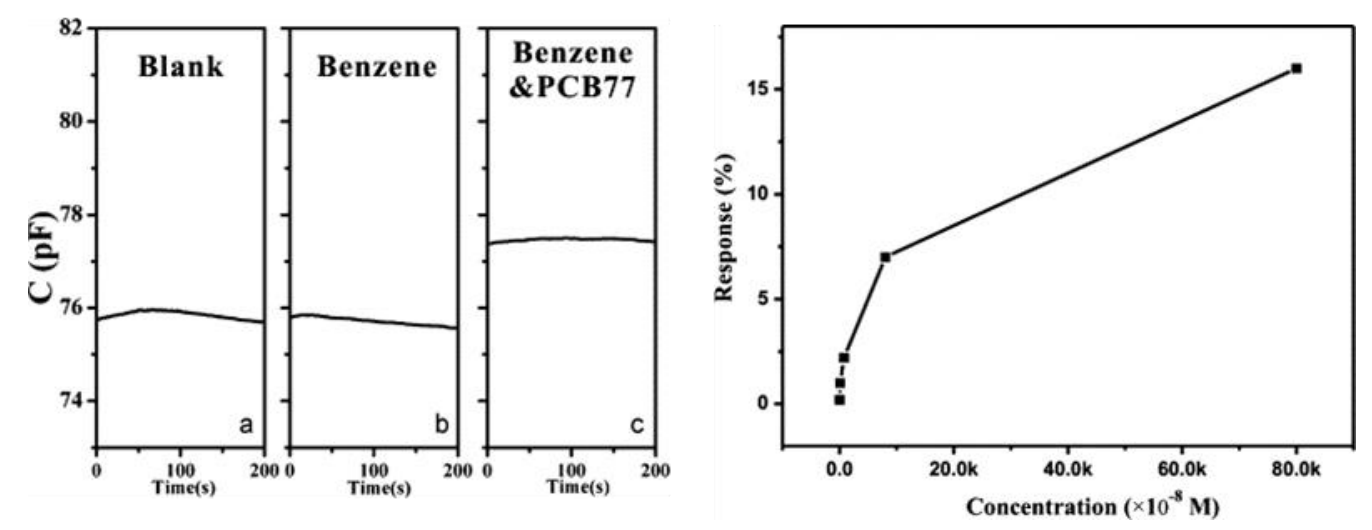

Figure 9. Nanoporous membranes as gas sensing platforms. (A) Schematically illustration of the set-up used for the preparation of an AAO nanoporous membrane based capacitive sensor. (B) Schematic illustration of the sensing mechanism. (C) (Left) capacitance values of (a) the blank PAA membrane and the ones after loading the methanol solutions of (b) benzene and (c) benzene \& PCB77; (Right) Responses of the capacitive sensor to $5 \mu \mathrm{L}$ PCB77 solutions for five different concentrations. Adapted with permission from ref. 143 . 


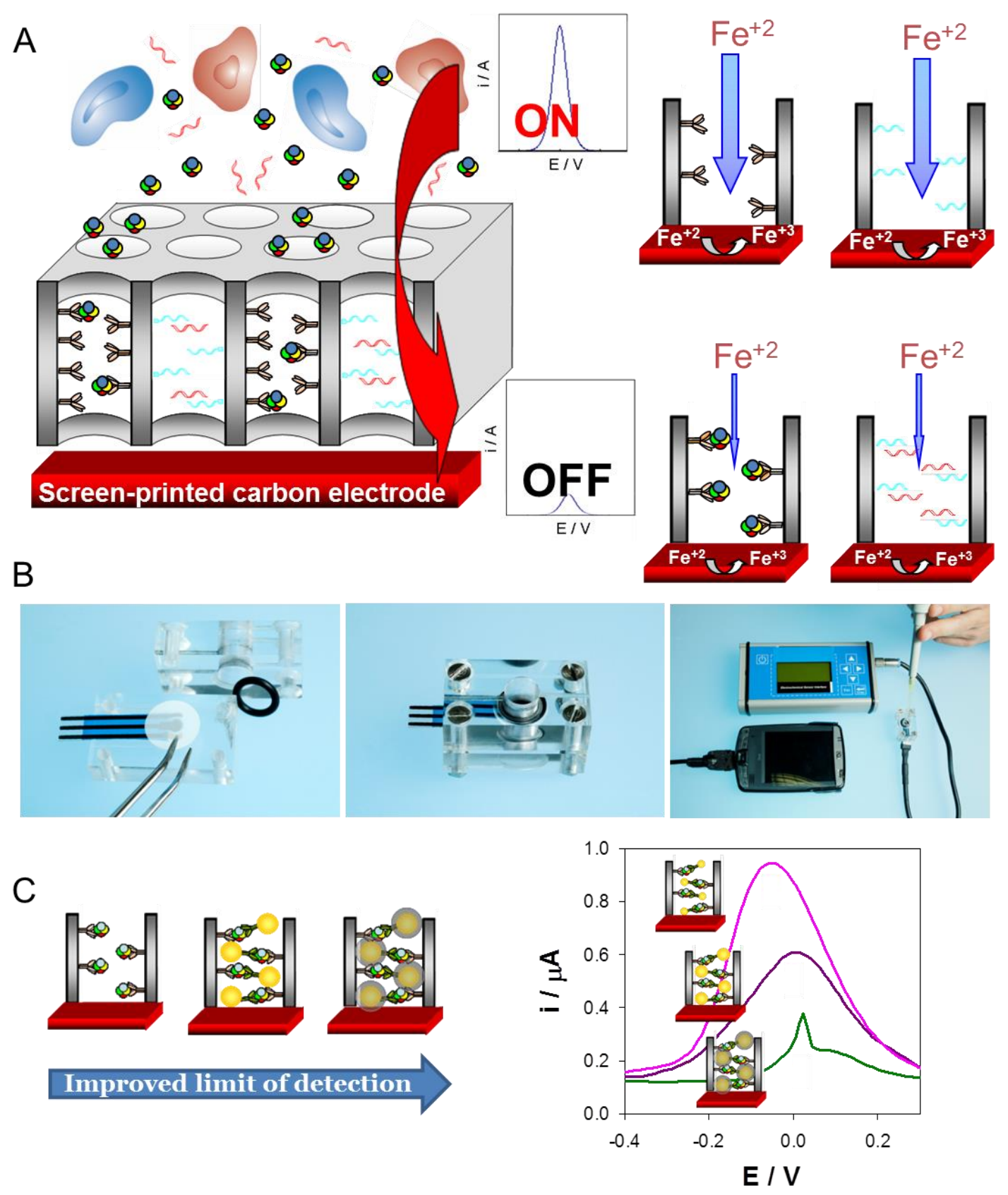

Figure 10. Principles of the voltammetric biosensing using nanochannel arrays. (A) Sensing principle in the absence ("On" response) and presence ("Off" response) of the specific biomolecule in the sample. (B) Pictures of the electrochemical cell set-up. (C) Illustration of the effect of different sized gold nanoparticle (AuNP) tags and silver deposition on the nanochannel blockage and the protein detection limit (left) and differential pulse voltammograms recorded in $1 \mathrm{mM} \mathrm{K}_{3}\left[\mathrm{Fe}(\mathrm{CN})_{6}\right] / 0.1 \mathrm{M} \mathrm{NaNO}_{3}$ for a $5 \mu \mathrm{g} / \mathrm{mL}$ solution of human IgG in sandwich immunoassays performed (from up to down) using AuNP tags of $20 \mathrm{~nm}, 80 \mathrm{~nm}$, and $80 \mathrm{~nm}+$ silver enhancement (right). Adapted with permission from refs. 144, 145 and 146. 

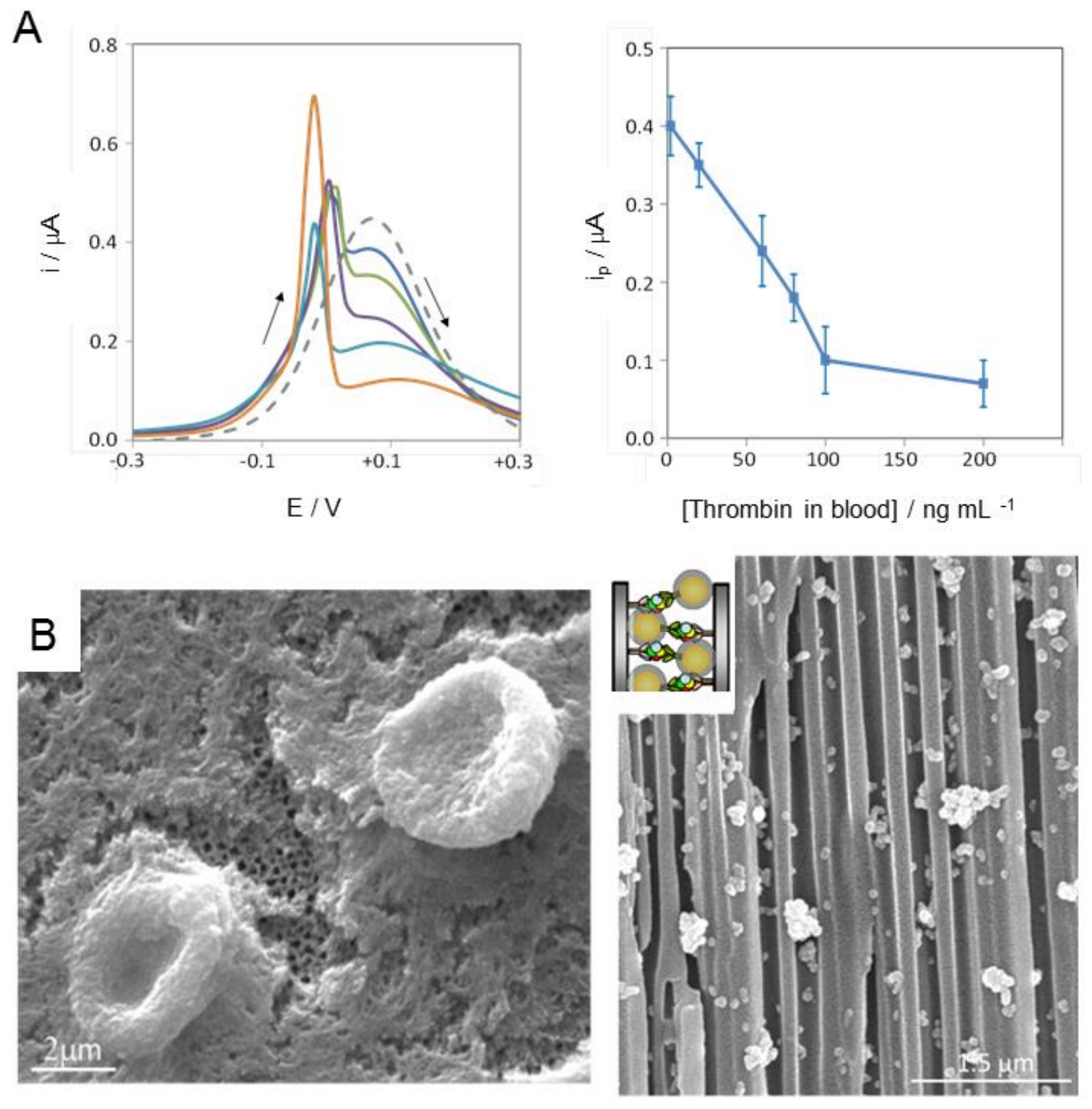

Figure 11. Voltammetric detection of protein biomarkers in blood using AAO nanoporous membranes. (A) (Left) Differential pulse voltammograms recorded in $1 \mathrm{mM}$ $\mathrm{K}_{3}\left[\mathrm{Fe}(\mathrm{CN})_{6}\right] / 0.1 \mathrm{M} \mathrm{NaNO}_{3}$ for blood samples containing spiked thrombin at concentrations of (up to down): 0 (dashed line), 2, 20, 60, 80 and $100 \mathrm{ng} / \mathrm{mL}$. (Right) effect of the concentration of thrombin spiked in blood on the analytical signal (right). (B) (Left) SEM top view of a 200-nm pore AAO membrane on which a drop of blood (30 $\mu \mathrm{L}$ ) was deposited. Blood cells as well as the nanopores are observed; (Right) SEM crosssectional view of the membrane modified with the aptamer and left to react with a blood sample containing $100 \mathrm{ng} / \mathrm{mL}$ of spiked thrombin. The sandwich assay is then completed with anti-thrombin/AuNPs followed by silver enhancement (silver crystals are observed). Adapted from with permission from ref. 148. 

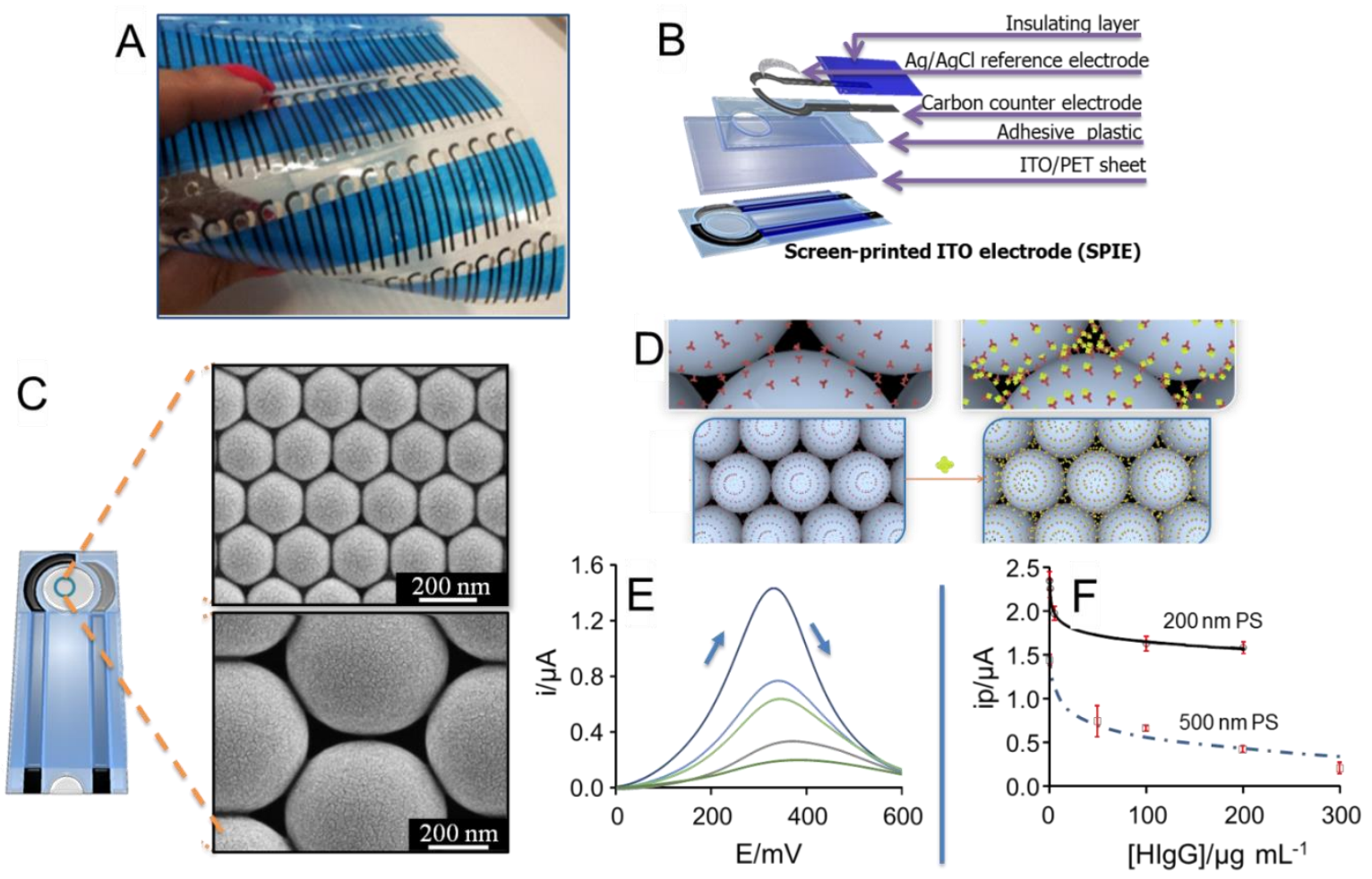

Figure 12. Voltammetric detection of proteins using nanochannel arrays created by selfassembled nanospheres. (A) Pictures of a sheet of screen-printed ITO electrodes (SPIEs). (B) Schematic representation of the different materials and layers which form the SPIE. (C) SEM images of a monolayer of $200 \mathrm{~nm}$ (up) and $500 \mathrm{~nm}$ (down) carboxylated polystyrene spheres (PS) on the working electrode of the SPIE. (D) Schematic representation (not in scale) of the sensing principle. (E) Differential pulse voltammograms recorded in $1 \mathrm{mM} \quad \mathrm{K}_{3}\left[\mathrm{Fe}(\mathrm{CN})_{6}\right] / 0.1 \mathrm{M} \quad \mathrm{NaNO}_{3}$ for different concentrations of human IgG, from top to bottom: 1, 50, 100, 200 and $300 \mu \mathrm{g} / \mathrm{mL}$ (SPIEs modified with $500 \mathrm{~nm}$ PS monolayer). (F) Relationship between the analytical signal and the concentration of HIgG for SPIEs modified with $200 \mathrm{~nm}$ PS monolayer (solid line) and $500 \mathrm{~nm}$ PS monolayer (dashed line). Adapted with permission from ref. 149. 


\section{REFERENCES}

1. J.S Erickson, F.S. Ligler, Analytical Chemistry: Home diagnostics to music, Nature 456 (2008) 178-179.

2. N.J Ronkainen, H.B. Halsall, W.R. Heineman, Electrochemical biosensors, Chem. Soc. Rev. 39 (2010) 1747-1763.

3. A. Merkoçi, Nanoparticles-based strategies for DNA, protein and cell sensors, Biosens. Bioelectron. 26 (2010) 1164-1177.

4. A. de la Escosura-Muñiz, C. Parolo, A. Merkoçi, Immunosensing using nanoparticles, Mater. Today 13 (2010) 24-34.

5. A. de la Escosura-Muñiz, A. Ambrosi, A. Merkoçi, Electrochemical analysis with nanoparticle-based biosystems. Trends Anal. Chem 27 (2008) 568-584.

6. D.W. Deamer, Characterization of nucleic acids by nanopore analysis, Acc. Chem. Res. 35(10) (2002) 817-825.

7. G. Wang, L. Wang, Y. Han, S. Zhou, X. Guan, Nanopore stochastic detection: diversity, sensitivity, and beyond, Acc. Chem. Res. 46(12) (2013) 2867-2877.

8. W. Guo, Y. Tian, L. Jiang, Asymmetric ion transport through ion-channel-mimetic solid-state nanopores, Acc. Chem. Res. 46(12) (2013) 2834-2846.

9. C.R. Martin, Z.S. Siwy, Learning nature's way: biosensing with synthetic nanopores, Science, 317(5836) (2007) 331-332.

10. J.E. Reiner, A. Balijepalli, J.W.F. Robertson, J. Campbell, J. Suehle, J.J. Kasianowicz, Disease detection and management via single nanopore-based sensors, Chem. Rev. 112 (2012) 6431-6451.

11. X. Hou, W. Guo, L. Jiang, Biomimetic smart nanopores and nanochannels, Chem. Soc. Rev. 40 (2011) 2385-2401.

12. Z.S. Siwy, S. Howorka, Engineered voltage-responsive nanopores, Chem. Soc. Rev. 39 (2010) 1115-1132.

13. J.J. Kasianowicz, J.W.F. Robertson, E.R. Chan, J.E. Reiner, V.W. Stanford, Nanoscopic porous sensors, Annu. Rev. Anal. Chem. 1 (2008) 737-766.

14. Howorka, Z.S. Siwy, Nanopore analytics: sensing of single molecules, Chem. Soc. Rev. 38 (2009) 2360-2384. 
15. A. Santos, T. Kumeria, D. Losic, Nanoporous anodic aluminum oxide for chemical sensing and biosensors, Trends Anal. Chem. 44 (2013) 25-38.

16. A. de la Escosura-Muñiz, A. Merkoçi, Nanochannels preparation and application in biosensing, ACS Nano 6(9) (2012) 7556-7583.

17. D.J. Idley, P.R. Stanfield, Ion channels: molecules in action; Cambrige University Press: New York, 1996.

18. W.H. Coulter, Means for counting particles suspended in a fluid. U.S. Patent 2656508 A, 1953.

19. W.H. Coulter, High speed automatic blood cell counter and cell size analyzer, Proc. Natl. Electronics Conf. 12 (1956) 1034.

20. W.H. Coulter, W.R. Hogg, Apparatus and method for measuring a dividing particle size of a particulate system, US Patent 3557352 A, 1971.

21. H. Bayley, Membrane-protein structure: Piercing insights, Nature 459 (2009) 651652.

22. S. Bezrukov, I. Vodyanoy, A. Parsegian, Counting polymers moving through a single ion channel, Nature 370 (1994) 279-281.

23. W.A. Vercoutere, S. Winters-Hilt, V.S. DeGuzman, D. Deamer, S.E. Ridino, J.T. Rodgers, H.E. Olsen, A. Marziali, M. Akeson, Discrimination among individual WatsonCrick base pairs at the termini of single DNA hairpin molecules, Nucleic Acids Res. 31(2003)1311-1318.

24. T. Albrecht, J.B. Edel, M. Winterhalter, New developments in nanopore researchrom fundamentals to applications, J. Phys. Condens. Matter. 22 (2010) 450301.

25. Bezrukov, J.J. Kasianowicz, Current noise reveals protonation kinetics and number of ionizable sites in an open protein ion channel, Phys. Rev. Lett. 70 (1993) 2352-2355.

26. J.J. Kasianowicz, S.M. Bezrukov, Biophys. J. 69 (1995) 94.

27. H. Bayley, P.S. Cremer, Stochastic sensors inspired by biology, Nature 413 (2001) 226-230.

28. R.J. Maitra, J. Kim, W.B. Dunbar, Recent advances in nanopore sequencing, Electrophoresis 33 (2012) 3418-3428. 
29. E. Atas, A. Singer, A. Meller, DNA sequencing and bar-coding using solid-state nanopores, Electrophoresis 33 (2012) 3437-3447.

30. A.L. Sisson, M.R. Shah, S. Bhosale, S. Matile, Synthetic ion channels and pores (2004-2005), Chem. Soc. Rev. 35 (2006) 1269-1286.

31. X. Hou, W. Guo, L. Jiang, Biomimetic smart nanopores and nanochannels, Chem. Soc. Rev. 40 (2011) 2385-2401.

32. Z.S. Siwy, S. Howorka, Engineered voltage-responsive nanopores, Chem. Soc. Rev. 39 (2010) 1115-1132.

33. A. Santos, G. Macías, J. Ferré-Borrull, J. Pallarès, L.F. Marsal, Photoluminescent enzymatic sensor based on nanoporous anodic alumina, ACS Applied Mater. Interfaces 4 (2012) 3584-3588.

34. A. Santos, T. Kumeria, D. Losic, Optically optimized photoluminescent and interferometric biosensors based on nanoporous anodic alumina: a comparison, Anal Chem 85 (2013) 7904-7911.

35. T. Kumeria, A. Santos, D. Losic, Ultrasensitive nanoporous interferometric sensor for label-free detection of gold (III) ions, ACS Appl. Mater. Interfaces. 5 (2013) 1178311790.

36. J.O. Arroyo, J. Andrecka, K.M. Spillane, N. Billington, Y. Takagi, J. R. Sellers, P. Kukura, Label-free, all-optical detection, imaging, and tracking of a single protein, Nano. Lett. 14 (2014) 2065-2070.

37. H. Bayley, L. Jayasinghe, Functional engineered channels and pores, Mol. Membr. Biol. 21 (2004) 209-220.

38. M. Lolicato, S. Reina, A. Messina, F. Guarino, M. Winterhalter, R. Benz, V. De Pinto, Generation of artificial channels by multimerization of $\beta$-strands from natural porin, Biol. Chem. 392 (2011) 617-624.

39. T.Z. Butler, M. Pavlenok, I.M. Derrington, M. Niederweis, J.H. Gundlach, Singlemolecule DNA detection with an engineered MspA protein nanopore, Proc. Natl. Acad. Sci. U.S.A. 105 (2008) 20647-20652. 
40. M. Montal, P. Mueller, Formation of bimolecular membranes from lipid monolayers and a study of their electrical properties, Proc. Natl. Acad. Sci. U.S.A. 69 (1972) 35613566.

41. L.P. Hromada, B.J. Nablo, J.J. Kasianowicz, M.A. Gaitan, D.L. DeVoe, Single molecule measurements within individual membrane-bound ion channels using a polymer-based bilayer lipid membrane chip, Lab Chip 8 (2008) 602-608.

42. J. Drexler, C. Steinem, Pore-suspending lipid bilayers on porous alumina investigated by electrical impedance spectroscopy, J. Phys. Chem. B 107 (2003) 1124511254.

43. R.E. Gyurcsányi, Chemically-modified nanopores for sensing, Trends Anal. Chem. 27 (2008) 627-639.

44. A.J Storm, J.H. Chen, X.S. Ling, H.W. Zandbergen, C. Dekker, Fabrication of solidstate nanopores with single-nanometre precision, Nat. Mater. 2 (2003) 537-540.

45. A. Romano-Rodríguez, F. Hernández-Ramírez, Dual-beam focused ion beam (FIB): a prototyping tool for micro and nanofabrication, Microelectron. Eng. 84 (2007) 789792.

46. J. Nakane, M. Wiggin, A. Marziali, A nanosensor for transmembrane capture and identification of single nucleic acid molecules, Biophys. J. 87 (2004) 615-621.

47. D. Stoddart, A. Heron, E. Mikhailova, G. Maglia, H. Bayley, Single-nucleotide discrimination in immobilized DNA oligonucleotides with a biological nanopore, Proc. Natl. Acad. Sci. U.S.A. 106 (2009) 7702-7707.

48. F. Purnell, J.J. Schmidt, Discrimination of single base substitutions in a DNA strand immobilized in a Biological Nanopore. ACS Nano 2009, 3, 2533-2538.

49. P. Chen, T. Mitsui, D.B Farmer, J. Golovchenko, R.G. Gordon, D. Branton, Atomic layer deposition to fine-tune the surface properties and diameters of fabricated nanopores, Nano Lett. 4 (2004) 1333-1337.

50. A.J. Storm, C. Storm, J. Chen, H. Zandbergen, J.F. Joanny, C. Dekker, Fast DNA translocation through a solid-state nanopore. Nano Lett. 5 (2005) 1193-1197.1

51. A.P. Ivanov, E. Instuli, C.M. Gilvery, G. Baldwin, D.W. Mc Comb, T. Albrecht, J.B. Edel, DNA tunneling detector embedded in a nanopore. Nano Lett. 11 (2011) 279-285. 
52. M. Ayub, A. Ivanov, J. Hong, P. Kuhn, E. Instuli, J.B. Edel, T. Albrecht, Precise electrochemical fabrication of sub-20 nm solid-state nanopores for single-molecule biosensing, J. Phys. Condens. Matter 22 (2010) 454128.

53. A.J. Storm, J.H. Chen, H.W. Zandbergen, C. Dekker, Translocation of double-strand DNA through a silicon oxide nanopore, Phys. Rev. E 71 (2005) 051903-1-051903-10.

54. B.M. Venkatesan, A.B. Shah, J.M. Zuo, R. Bashir, DNA sensing using nanocrystalline surface-enhanced Al2O3 nanopore sensors, Adv. Funct. Mater. 20 (2010) $1266-1275$.

55. B.M. Venkatesan, D. Estrada, S. Banerjee, X. Jin, V.E. Dorgan, M.H. Bae, N.R. Aluru, E. Pop, R. Bashir, Stacked graphene-A12O3 nanopore sensors for sensitive detection of DNA and DNA protein complexes, ACS Nano 6 (2012) 441-450.

56. M. Wanunu, W. Morrison, Y. Rabin, A.Y. Grosberg, A. Meller, Electrostatic focusing of unlabelled DNA into nanoscale pores using a salt gradient, Nat. Nanotechnol. 5 (2010) 160-165.

57. D. Pedone, M. Langecker, G. Abstreiter, U. Rant. A pore-cavity-pore device to trap and investigate single nanoparticles and DNA molecules in a femtoliter compartment: confined diffusion and narrow escape, Nano Lett. 11 (2011) 1561-1567.

58. M. Langecker, D. Pedone, F.C0 Simmel, U. Rant, Electrophoretic time-of-flight measurements of single DNA molecules with two stacked nanopores, Nano Lett. 11 (2011) 5002-5007.

59. V. Mussia, P. Fanzio, L. Repetto, G. Firpo, S. Stigliani, G.P. Tonini, U. Valbusa, DNA-dressed nanopore" for complementary sequence detection, Biosens. Bioelectron. 29 (2011) 125-131.

60. A. Singer, M. Wanunu, W. Morrison, H. Kuhn, M. Frank-Kamenetskii, A. Meller, Nanopore based sequence specific detection of duplex DNA for genomic profiling, Nano Lett. 10 (2010) 738-742.

61. J. Kasianowicz, E. Brandin, D. Branton, D. Deamer, Characterization of individual polynucleotide molecules using a membrane channel, Proc. Natl. Acad. Sci. USA 93 (1996) 13770-13773.

62. D. Branton, D.W. Deamer, A. Marziali, H. Bayley, S.A. Benner, T. Butler, M. Di Ventra, S. Garaj, A. Hibbs, X. Huang S.B. Jovanovich, P.S. Krstic, S. Lindsay, X.S. Ling, 
C.H. Mastrangelo, A. Meller, J.S. Oliver, Y.V. Pershin, J.M. Ramsey, R. Riehn, G.V. Soni, V. Tabard-Cossa, M. Wanunu, M. Wiggin, J.A. Schloss, The potential and challenges of nanopore sequencing, Nat. Biotechnol. 26 (2008) 1146-1153.

63. B.M. Venkatesan, R. Bashir, Nanopore sensors for nucleic acid analysis, Nat. Nanotechnol. 6 (2011) 615-624.

64. S. Howorka, S. Cheley, H. Bayley, Sequence-specific detection of individual DNA strands using engineered nanopores, Nat. Biotechnol. 19 (2001) 636-639.

65. Oxford Nanopores Tecnologies Ltd. https://www.nanoporetech.com/ (accessed October 21, 2015).

66. D.J. Munroe, T.J.R. Harris, Third-generation sequencing fireworks at Marco Island, Nat. Biotechnol. 28 (2010) 426-428.

67. J. Clarke, H.C. Wu, L. Jayasinghe, A. Patel, S. Reid, H. Bayley, Continuous base identification for single-molecule nanopore DNA sequencing, Nat. Nanotechnol. 4 (2009) 265-270.

68. Y. He, M. Tsutsui, C. Fan, M. Taniguchi, T. Kawai, Controlling DNA translocation through gate modulation of nanopore wall surface charges, ACS Nano 5(7) (2011) 55095518.

69. A. Barati Farimani, M. Heiranian, N.R. Aluru, Electromechanical signatures for DNA sequencing through a mechanosensitive nanopore, J. Phys. Chem. Lett. 6 (2015) 6 $650-657$.

70. L. Movileanu, S. Howorka, O. Braha, H. Bayley, Detecting protein analytes that modulate transmembrane movement of a polymer chain within a single protein pore. Nat. Biotechnol. 18 (2000) 1091-1095.

71. S. Howorka, J. Nam, H. Bayley, D. Kahne, Stochastic detection of monovalent and bivalent protein-ligand interactions, Angew. Chem., Int. Ed. 43 (2004) 842-846.

72. S. Cheley, H. Xie, H. Bayley, A genetically encoded pore for the stochastic detection of a protein kinase. Chem.BioChem 7 (2006) 1923-1927.

73. H. Xie, O. Braha, L.Q. Gu, S. Cheley, H. Bayley, Single-molecule observation of the catalytic subunit of cAMP dependent protein kinase binding to an inhibitor peptide, Chem. Biol. 12 (2005) 109-120. 
74. D. Rotem, L. Jayasinghe, M. Salichou, H. Bayley, Protein detection by nanopores equipped with aptamers, J. Am. Chem. Soc. 134 (2012) 2781-2787.

75. G. Oukhaled, J. Mathé, A.L. Biance, L. Bacri, J.M. Betton, D. Lairez, J. Pelta, L. Auvray, L. Phys. Rev. Lett. 98 (2007) 158101.

76. L. Payet, M. Martinho, M. Pastoriza-Gallego, J.M. Betton, L. Auvray, J. Pelta, J. Mathé, Thermal unfolding of proteins probed at the single molecule level using nanopores, Anal. Chem. 84 (2012) 4071-4076.

77. C.B. Rosen, D. Rodriguez-Larrea, H. Bayley, Single-molecule site-specific detection of protein phosphorylation with a nanopore, Nat. Biotechnol. 32 (2014) 179-181.

78. J. Nivala, L. Mulroney, G. Li, J. Schreiber, M. Akeson, Discrimination among protein variants using an unfoldase-coupled nanopore, ACS Nano 8 (2014) 12365-12375.

79. M. Firnkes, D. Pedone, J. Knezevic, M. Döblinger, U. Rant, Electrically facilitated translocations of proteins through silicon nitride nanopores: conjoint and competitive action of diffusion, electrophoresis, and electroosmosis, Nano Lett. 10 (2010) 2162-2167.

80. W. Li, N.A.W. Bell, S. Hernández-Ainsa, V.V. Thacker, A.M. Thackray, R. Bujdoso, U.F. Keyser, Single molecule protein detection by glass nanopores, ACS Nano $7(2013)$ 4129-4134.

81. J. Larkin, R.Y. Henley, M. Muthukumar, J.K. Rosenstein, M. Wanunu, Highbandwidth protein analysis using solid-state nanopores. Biophys. J. 106 (2014) 696-704.

82. R. Wei, V. Gatterdam, R. Wieneke, R. Tampe, U. Rant, Stochastic sensing of proteins with receptor-modified solid-state nanopores, Nat. Nanotechnol. 7 (2012) 257263.

83. M. Ali, S. Nasir, Q.H. Nguyen, J.K. Sahoo, M.N. Tahir, W. Tremel, W. Ensinger, Metal ion affinity-based biomolecular recognition and conjugation inside synthetic polymer nanopores modified with iron terpyridine complexes. J. Am. Chem. Soc. 133 (2011) 17307-17314.

84. P. Fanzio, V. Mussi, M. Menotta, G. Firpo, L. Repetto, P. Guida, E. Angeli, M. Magnani, U. Valbusa, Selective protein detection with a dsLNA-functionalized nanopore, Biosens. Bioelectron. 64 (2015) 219-226. 
85. N.A.W. Bell, U.F. Keyser, Specific protein detection using designed DNA carriers and nanopores, J. Am. Chem. Soc. 137 (2015) 2035-2041.

86. M. Schwarz, The adsorption of coliphage lambda to its host: effect of variations in the surface density of receptor and in phage-receptor affinity, J. Mol. Biol. 103 (1976) $521-536$.

87. P.A. Gurnev, A. Oppenheim, M. Winterhalter, S.M. Bezrukov, Docking of a single phage lambda to its membrane receptor maltoporin as a time-resolved event. J. Mol. Biol. 359 (2006) 1447-1455.

88. K. Zhou, L. Li, Z. Tan, Characterization of hepatitis B virus capsids by resistivepulse sensing, J. Am. Chem. Soc. 133 (2011) 1618-1621.

89. Z. Harms, K. Mogensen, Nanofluidic devices with two pores in series for resistivepulse sensing of single virus capsids, Anal. Chem. 83 (2011) 9573-9578.

90. J.D. Uram, K. Ke, A.J. Hunt, M. Mayer, Submicrometer pore-based characterization and quantification of antibody-virus interactions, Small 2 (2006) 967-972.

91. A. McMullen, H.W. de Haan, J.X. Tang, D. Stein, Stiff filamentous virus translocations through solid-state nanopores, Nature Communications 5 (2014) 4171.

92. Z. Siwy, L. Trofin, P. Kohli, L.A. Baker, C. Trautmann, C.R. Martin, Protein biosensors based on biofunctionalized conical gold nanotubes, J. Am. Chem. Soc. 127 (2005) 5000-5001.

93. Y. Wang, V. Montana, V. Grubišić, R.V. Stout Jr., V. Parpura, L.Q. Gu, Nanopore sensing of botulinum toxin type B by discriminating an enzymatically cleaved peptide from a synaptic protein synaptobrevin 2 derivative, ACS Appl. Mater. Interfaces (7) 2015, 184-192.

94. A. Liu, Q. Zhao, X. Guan, Stochastic nanopore sensors for the detection of terrorist agents: Current status and challenges, Anal. Chim. Acta 675 (2010) 106-115.

95. O. Braha, L.Q Gu, L. Zhou, X.F. Lu, S. Cheley, H. Bayley, Simultaneous stochastic sensing of divalent metal ions, Nat. Biotechnol. 18 (2000) 1005-1007.

96. S. Wen, T. Zeng, L. Liu, K. Zhao, Y. Zhao, X. Liu, H.C. Wu, Highly densitive and selective DNA-based detection of mercury(II) with $\alpha$-hemolysin nanopore, J. Am. Chem. Soc. 133 (2011) 18312-18317. 
97. A. K. Geim, K. S. Novoselov, The rise of graphene, Nat. Mater. 6 (2007) 183.

98. A.H. Castro-Neto, F. Guinea, N.M.R. Peres, K.S. Novoselov, A.K. Geim, The electronic properties of graphene, Rev. Mod. Phys. 81 (2009) 109.

99. S. Garaj, S. Liu, J.A. Golovchenko, D. Branton, Molecule-hugging graphene nanopores, Proc. Natl. Acad. Sci. U.S.A. 110 (2013) 12192-12196.

100.Q. Xu, M.Y. Wu, G.F. Schneider, L. Houben, S.K. Malladi, C. Dekker, E. Yucelen, R.E. Dunin-Borkowski, H.W. Zandbergen, Controllable atomic scale patterning of freestanding monolayer graphene at elevated temperature, ACS Nano 7 (2013) 15661572.

101.S. Garaj, W. Hubbard,; A. Reina, J. Kong, D. Branton, J.A. Golovchenko, Graphene as a subnanometre trans-electrode membrane, Nature 467 (2010) 190-194.

102.F. Traversi, C. Raillon, S.M. Benameur, K. Liu, S. Khlybov, M. Tosun, D. Krasnozhon, A. Kis, A. Radenovic, Detecting the translocation of DNA through a nanopore using graphene nanoribbons, Nat. Nanotechnol. 8 (2013) 939-945.

103.J. Shim, J.A. Rivera, R. Bashir, Electron beam induced local crystallization of $\mathrm{HfO}_{2}$ nanopores for biosensing applications, Nanoscale, 5 (2013) 10887-10893.

104.S. Husale, S. Sahoo, A. Radenovic, F. Traversi, P. Annibale, A. Kis, Ssdna binding reveals the atomic structure of graphene, Langmuir 26 (2010) 18078-18082.

105.K. Watanabe, T. Taniguchi, H. Kanda, Direct-bandgap properties and evidence for ultraviolet lasing of hexagonal boron nitride single crystal, Nat. Mater. 3 (2004) 404409 .

106. L. Song, L.J. Ci, H. Lu, P.B. Sorokin, C.H. Jin, J. Ni, A.G. Kvashnin, D.G. Kvashnin, J. Lou, B.I. Yakobson, P.M. Ajayan, Large scale growth and characterization of atomic hexagonal boron nitride layers, Nano Lett. 10 (2010) 3209-3215.

107.S. Liu, B. Lu, Q. Zhao, J. Li, T. Gao, Y. Chen, Y. Zhang, Z. Liu, Z. Fan, Y. Yang, L. You, D. Yu, Boron nitride nanopores: highly sensitive DNA single-molecule detectors, Adv. Mater. 25 (2013) 4549-4554.

108.K. Liu, J. Feng, A. Kis, A. Radenovic, Atomically thin molybdenum disulfide nanopores with high sensitivity for DNA translocation, ACS Nano 8(3) (2014) 2504-2511. 
109.J. Feng, K. Liu, M. Graf, M. Lihter, R.D. Bulushev, D. Dumcenco, D.T.L. Alexander, D. Krasnozhon, T. Vuletic, A. Kis, A. Radenovic, Electrochemical reaction in single layer MoS2: Nanopores opened atom by atom, Nano Lett. 15 (2015) 3431-3438.

110.G.F. Schneider, S.W. Kowalczyk, V.E. Calado, G. Pandraud, H.W. Zandbergen, L.M.K. Vandersypen, C. Dekker, DNA translocation through graphene nanopores, Nano Lett. 10 (2010) 3163-3167.

111.C.A. Merchant, K. Healy, M. Wanunu, V. Ray, N. Peterman, J. Bartel, M.D. Fischbein, K. Venta, Z. Luo, A.T.C. Johnson, M. Drndić, DNA translocation through graphene nanopores, Nano Lett. 10 (2010) 2915-2921.

112.G.T. Feliciano, C. Sanz-Navarro, M.D. Coutinho-Neto, P. Ordejón, R.H. Scheicher, A.R. Rocha, Capacitive DNA detection driven by electronic charge fluctuations in a graphene nanopore, Physiscal Review Applied 3 (2015) 034003.

113.H. Sadeghi, L. Algaragholy, Y. Pope, S. Bailey, D. Visontai, D. Manrique, J. Ferrer, V. Garcia-Suarez, S. Sangtarash, C.L. Lambert, Graphene sculpturene nanopores for DNA nucleobase sensing, J. Phys. Chem. B 118 (2014) 6908-6914.

114.T. Nelson, B. Zhang, O.V. Prezhdo, Detection of nucleic acids with graphene nanopores: Ab Initio characterization of a novel sequencing device. Nano Lett. 10 (2010) $3237-3242$.

115.K. Hu, D. Lan, X. Li, S. Zhang, Electrochemical DNA biosensor based on nanoporous gold electrode and multifunctional encoded DNA-Au bio bar codes, Anal. Chem. 80 (2008) 9124-9130.

116. P. Kohli, C.C. Harrell, Z. Cao, R. Gasparac, W. Tan, C.R. Martin, DNAfunctionalized nanotube membranes with single-base mismatch selectivity, Science 305 (2004) 984-985.

117. A. de la Escosura-Muñiz, M. Espinoza Castañeda, A. Merkoçi, Protein and DNA electrochemical sensing using anodized aluminum oxide nanochannel arrays. Nanoporous Alumina: fabrication, structure, properties and applications. Editorial: Springer (Ed. D. Losic and A. Santos). Chapter 9 (2015) 271-291.

118. H. Masuda, H. Tanaka, N. Baba. Preparation of porous material by replacing microstructure of anodic alumina film with metal, Chem. Lett. 4 (1990) 621-622. 
119. A. Santos, P. Formentín, J. Ferré-Borrull, J. Pallarès, L.F. Marsal, Nanoporous anodic alumina obtained without protective oxide layer by hard anodization, Materials Letters 67(1) (2012) 296-299.

120. A.M.M. Jani, E.J. Anglin, S.J.P. McInnes, D. Losic, J.G. Shapter, N.H. Voelcker, Nanoporous anodic aluminium oxide membranes with layered surface chemistry, Chem. Commun. (2009) 3062-3064.

121. T.R.B. Foong, A. Sellinger, X. Hu, Origin of the bottlenecks in preparing anodized aluminum oxide (AAO) templates on ITO glass, ACS Nano 2 (2008) 2250-2256.

122. A. Debrassi, A. Ribbera, W.M. De Vos, T. Wennekes, H. Zuilhof, Stability of (bio)functionalized porous aluminum oxide, Langmuir 30 (2014) 1311-1320.

123. L.H. Qian, R. Mookherjee, Convective assembly of linear gold nanoparticle arrays at the micron scale for surface enhanced Raman scattering, Nano Res. 4 (2011) 11171128.

124. H. Chang, S.H. Joo, C. Pak, Synthesis and characterization of mesoporous carbon for fuel cell applications, J. Mater. Chem. 17 (2007) 3078-3088.

125. X. Wang, S. Xu, M. Cong, H. Li, Y. Gu, W. Xu, Hierarchical structural nanopore arrays fabricated by pre-patterning aluminum using nanosphere lithography, Small 8 (2012) 972-976.

126. V.M. Guérin, J. Elias, T.T. Nguyen, L. Philippe, T. Pauporté, Ordered networks of ZnO-nanowire hierarchical urchinlike structures for improved dye-sensitized solar cells, Phys. Chem. Chem. Phys. 14 (2012) 12948-12955.

127. J .Elias, C. Lévy-Clément, M. Bechelany, J. Michler, G. Wang, Z. Wang, L. Philippe, Hollow urchin-like $\mathrm{ZnO}$ thin films by electrochemical deposition, Adv. Mater. 22 (2010) 1607-1612.

128. O.A. Saleh, L.L. Sohn, An artificial nanopore for molecular sensing, Nano Lett. 3 (2003) 37-38.

129. C.C. Chao, T.C. Wang, R.M. Ho, P. Georgopanos, A. Avgeropoulos, E.L. Thomas, Robust block copolymer mask for nanopatterning polymer films, ACS Nano 4 (2010) 2088-2094. 
130. D. Chanda, K. Shigeta, S. Gupta, T. Cain, A. Carlson, A. Mihi, A.J. Baca, G.R. Bogart, P. Braun, J.A. Rogers, Large-area flexible 3D optical negative index metamaterial formed by nanotransfer printing, Nat. Nanotechnol. 6 (2011) 402-407.

131.I. Vlassiouk, P. Takmakov, S. Smirnov, Sensing DNA hybridization via ionic conductance through a nanoporous electrode, Langmuir 21 (2005) 4776-4778.

132. P. Takmakov, I. Vlassiouk, S. Smirnov, Sensing DNA hybridization via ionic conductance through a nanoporous electrode, Analyst 131 (2006) 1248-1253.

133. S. Wu, W.W. Ye, M. Yang, M. Taghipoor, R. Meissner, J. Brugger, P. Renaud, Impedance sensing of DNA immobilization and hybridization bymicrofabricated alumina nanopore membranes, Sens. Actuators B 216 (2015) 105-112.

134. J. Deng, C.S. Toh, Impedimetric DNA biosensor based on a nanoporous alumina membrane for the detection of the specific oligonucleotide sequence of Dengue Virus, Sensors 13 (2013) 7774-7785.

135. W.W. Ye, J.Y. Shi, C.Y. Chan, Y. Zhang, M. Yang, A nanoporous membrane based impedance sensing platform for DNA sensing with gold nanoparticle amplification, Sens. Actuators B 193 (2014) 877-882.

136. K. Kant, J. Yu, C. Priest, J.G. Shapter, D. Losic, Impedance nanopore biosensor: influence of pore dimensions on biosensing performance, Analyst 139 (2014) 1134-1140. 137. F. Tan, P.H.M Leung, Z. Liu, Y. Zhang, L. Xiao, W. Ye, X. Zhang, L. Yi, M. Yang, A PDMS microfluidic impedance immunosensor for E. coli O157:H7 and Staphylococcus aureus detection via antibody-immobilized nanoporous membrane, Sens. Actuators B 159 (2011) 328-335.

138. W. Ye, J. Guo, S. Chen, M. Yang, Nanoporous membrane based impedance sensors to detect the enzymatic activity of botulinum neurotoxin A, J. Mater. Chem. B 1 (2013) 6544-6550.

139. Z. Yang, S. Si, C. Zhang, Study on the activity and stability of urease immobilized onto nanoporous alumina membranes, Micropor. Mesopor. Mater. 111 (2008) 359-366.

140. Y. Jiang, N. Liu, W. Guo, F. Xia, L. Jiang, Highly-efficient gating of solid-state nanochannels by DNA supersandwich structure containing ATP aptamers: a nanofluidic IMPLICATION logic device, J. Am. Chem. Soc. 134 (2012) 15395-15401. 
141. L. Juhász, J. Mizsei, Humidity sensor structures with thin film porous alumina for on-chip integration, Thin Solid Films 517 (2009) 6198-6201.

142. V. Khatko, G. Gorokh, A. Mozalev, D. Solovei, E. Llobet, X. Vilanova, X. Correig, Tungsten trioxide sensing layers on highly ordered nanoporous alumina template, Sens. Actuators B 118 (2006) 255-265.

143. Z. Jin, F. Meng, J. Liu, M. Li, L. Kong, J. Liu, A novel porous anodic alumina based capacitive sensor towards trace detection of PCBs, Sens. Actuators B 157(2) (2011) 641646.

144. A. de la Escosura-Muñiz, A. Merkoçi, Label-free voltammetric immunosensor using a nanoporous membrane based platform, Electrochem. Comm. 12 (2010) 859-863.

145. A. de la Escosura-Muñiz, A. Merkoçi, Nanoparticle based enhancement of electrochemical DNA hybridization signal using nanoporous electrodes. Chem. Commun. 46 (2010) 9007-9009.

146. A. de la Escosura-Muñiz, A. Merkoçi, A nanochannel/nanoparticle-based filtering and sensing platform for direct detection of a cancer biomarker in blood, Small 7 (2011) 675-682.

147. M. Espinoza-Castañeda, A. de la Escosura-Muñiz, A. Chamorro, C. de Torres, A. Merkoçi, Nanochannel array device operating through Prussian blue nanoparticles for sensitive label-free immunodetection of a cancer biomarker, Biosens. Bioelectron. 67 (2015) 107-114.

148. A. de la Escosura-Muñiz, W. Chunglok, W. Surareungchai, A. Merkoçi, Nanochannels for diagnostic of thrombin-related diseases in human blood, Biosens. Bioelectron. 40 (2013) 24-31.

149. A. de la Escosura-Muñiz, M. Espinoza-Castañeda, M. Hasegawa, L. Philippe, A. Merkoçi, Assembled nanoparticles-based nanochannels onto a plastic flexible substrate for label-free immunosensing, Nano Research 8(4) (2015) 1180-1188. 